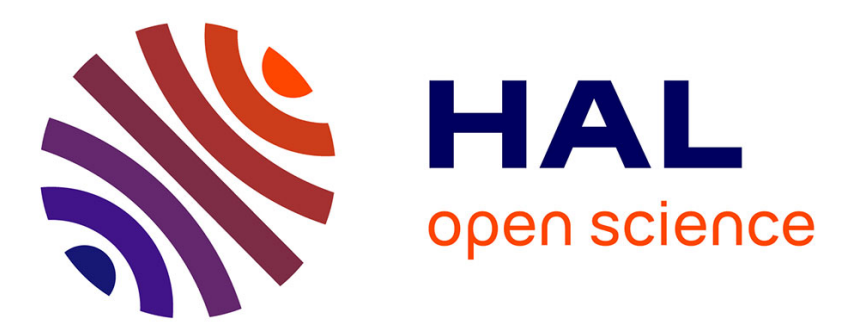

\title{
Understanding the Multiconfigurational Ground and Excited States in Lanthanide Tetrakis Bipyridine Complexes from Experimental and CASSCF Computational Studies
}

Robert Halbach, Grégory Nocton, Jorge Amaro-Estrada, Laurent Maron, Corwin A Booth, Richard A Andersen

\section{To cite this version:}

Robert Halbach, Grégory Nocton, Jorge Amaro-Estrada, Laurent Maron, Corwin A Booth, et al.. Understanding the Multiconfigurational Ground and Excited States in Lanthanide Tetrakis Bipyridine Complexes from Experimental and CASSCF Computational Studies. Inorganic Chemistry, 2019, 58

(18), pp.12083-12098. 10.1021/acs.inorgchem.9b01393 . hal-02289195

\section{HAL Id: hal-02289195 \\ https://hal.science/hal-02289195}

Submitted on 11 Nov 2020

HAL is a multi-disciplinary open access archive for the deposit and dissemination of scientific research documents, whether they are published or not. The documents may come from teaching and research institutions in France or abroad, or from public or private research centers.
L'archive ouverte pluridisciplinaire HAL, est destinée au dépôt et à la diffusion de documents scientifiques de niveau recherche, publiés ou non, émanant des établissements d'enseignement et de recherche français ou étrangers, des laboratoires publics ou privés. 


\title{
Understanding the Multiconfigurational
}

\section{Ground - and Excited States in Lanthanide}

\author{
Tetrakis Bipyridine Complexes from
}

\section{Experimental and CASSCF Computational}

\section{Studies}

Robert L. Halbach, ${ }^{a}$ Grégory Nocton, ${ }^{* a, b, c}$ Jorge I. Amaro-Estrada, ${ }^{d}$ Laurent Maron, ${ }^{d}$ Corwin H. Booth, ${ }^{b}$ and Richard A. Andersen $*^{a, b}$

a) Department of Chemistry, University of California, Berkeley, California 94720, United States.

b) Chemical Sciences Division, Lawrence Berkeley National Laboratory, Berkeley, California 94720, United States.

c) LCM, CNRS, Ecole polytechnique, Institut Polytechnique de Paris, 91128 Palaiseau, France.

d) LPCNO, UMR 5215, Université de Toulouse-CNRS, INSA, UPS, 31000 Toulouse, France. 


\section{ABSTRACT.}

An alternative synthesis for $\mathrm{M}\left(\kappa^{2}-\text { bipy }\right)_{4}, \mathrm{M}=\mathrm{La}, \mathrm{Ce}$ and $\left[\mathrm{Li}(\mathrm{thf})_{4}\right]\left[\mathrm{M}\left(\kappa^{2}-\text { bipy }\right)_{4}\right], \mathrm{M}=\mathrm{Tb}$, Dy, and the crystal structures for $\mathrm{M}=\mathrm{La}$ and $\mathrm{Ce}$, and $\mathrm{Tb}$ are described. The isomorphous and isostructural neutral molecules, $\mathrm{M}=\mathrm{La}$ and $\mathrm{Ce}$, are polymeric in the solid-state, as are those of $\mathrm{M}=\mathrm{Sm}$ and $\mathrm{Eu}$, which were reported in earlier work. The polymeric network is built from eight coordinate units whose geometry in all four cases is that of a square prism. The known molecules, $\mathrm{M}=\mathrm{Yb}$ and $\mathrm{Lu}$ are also polymeric but the eight coordinate units have dodecahedral geometries. The structure of the anions in the separated ion pair, $\left[\mathrm{Li}(\mathrm{thf})_{4}\right]\left[\mathrm{M}\left(\kappa^{2}-\text { bipy }\right)_{4}\right]$, in which $\mathrm{Tb}$ is reported in this work and $\mathrm{Lu}$ is known, are monomeric with geometries that are between that of a square antiprism and a dodecahdron. The electronic structure, from CASSCF multireference quantum mechanical calculations show that the electronic ground states for $\mathrm{M}=\mathrm{La}$ and $\mathrm{Lu}$ are multiconfigurational spin doublets and those for the $\mathrm{M}=\mathrm{Ce}$ and $\mathrm{Yb}$ are multiconfigurational spin triplets. This is confirmed by magnetic susceptibility studies as a function of temperature that are consistent with the metals (La, $\mathrm{Ce}, \mathrm{Sm}, \mathrm{Tb}, \mathrm{Dy}, \mathrm{Yb}$ and $\mathrm{Lu}$ ) being multiconfigurational, as are the $\mathrm{L}_{\mathrm{III}}$-edge XANES spectra $(\mathrm{Ce}, \mathrm{Yb})$ and divalent for Eu. The multiconfigurational nature of the ground states, developed from CASSCF molecular orbital calculations, renders a single Lewis structure and a single reference molecular orbital representation misleading. The results from the multireference calculations are extended to the other lanthanide molecules and are the genesis of a new model for understanding the magnetic properties of these molecules. 


\section{INTRODUCTION.}

The 4f-block metal compounds with 2,2'-bipyridine of empirical composition $\mathrm{M}\left(\kappa^{2} \text {-bipy }\right)_{4}$, $\mathrm{M}=\mathrm{La}, \mathrm{Ce}$, and $\mathrm{Nd}$ were prepared fifty years ago by Herzog. ${ }^{1-2}$ These compounds were prepared as part of a systematic investigation of the reaction of the metal salts with $\operatorname{Li}_{2}$ (bipy) and bipy in thf. ${ }^{3}$ The compounds with $\mathrm{M}=\mathrm{Eu}, \mathrm{Yb}$ were prepared shortly thereafter from the metals dissolved in liquid ammonia and bipyridine. ${ }^{4}$ The synthesis of the remainder of the $4 \mathrm{f}-$ block metals, except Pm, was published in 2000, adapting the synthetic methodology used by Herzog, i.e. using metal iodides or bis-trimethylsilyl amides as starting materials. ${ }^{5}$

The compounds are deeply colored, often described as black, air and moisture sensitive solids that are not volatile. They are insoluble in hydrocarbon and ethereal solvents. The solid-state effective magnetic moments ( $\mu_{\text {eff }}$ ) at room temperature for $\mathrm{M}=\mathrm{La}, \mathrm{Ce}$, and $\mathrm{Nd}$ were $1.82 \mu_{\mathrm{B}}$, $2.85 \mu_{\mathrm{B}}$ and $3.62 \mu_{\mathrm{B}}$, respectively ${ }^{1-2}$ show that the compounds are not based on the metals in their zero oxidation states. The room temperature solution $(\mathrm{MeCN})$ magnetic moments for $\mathrm{Eu}$ and $\mathrm{Yb}$ of $5.8 \mu_{\mathrm{B}}$ and $2.8 \mu_{\mathrm{B}}$, respectively, were ascribed to antiferromagnetic coupling between the metal-based spins and the ligand-based spins, the latter being formulated as bipy radical anions. ${ }^{4}$ The UV-Vis spectra of $\mathrm{M}=\mathrm{Tb}$ and $\mathrm{Yb}$ clearly show signatures of bipy radical anions but their complexity rendered a detailed interpretation impossible. ${ }^{6}$ The solidstate effective moments $\left(\mu_{\mathrm{eff}}\right)$ at room temperature were reported for the entire $4 \mathrm{f}$-block metals (except Pm) along with crystals structures of Sm, Eu, Yb, and Lu. ${ }^{5,7}$ The $\mu_{\text {eff }}$ values agree with those reported by Herzog but disagree with those by Feistel ${ }^{4}$ (see discussion) and were interpreted according to the Lewis structure $\left[\mathrm{M}(\mathrm{III})(\text { bipy })^{2-}(\text { bipy })^{-}(\text {(bipy })_{2}\right]$, except for Eu, which was based on $\mathrm{Eu}(\mathrm{II})$. The bipyridine ligands are clearly non-innocent or perhaps more descriptively referred to as redox active ${ }^{8}$ but a deeper level of understanding of the electronic structure was not developed. 
This article describes a new synthesis of $\mathrm{M}\left(\kappa^{2}-\text { bipy }\right)_{4}, \mathrm{M}=\mathrm{La}, \mathrm{Ce}$, and $\left[\mathrm{Li}(\mathrm{thf})_{4}\right]\left[\mathrm{M}\left(\kappa^{2}-\right.\right.$ bipy) 4 ], $\mathrm{M}=\mathrm{Tb}$, Dy, the $\mathrm{X}$-ray crystal structures of $\mathrm{La}, \mathrm{Ce}$, and $\mathrm{Tb}$, variable temperature magnetic susceptibilities, EPR and $\mathrm{L}_{\mathrm{III}}$ edge XANES for $\mathrm{Ce}$ and $\mathrm{Yb}$. $\mathrm{A}$ MO model is developed for the $\mathrm{La}, \mathrm{Ce}, \mathrm{Yb}$, and $\mathrm{Lu}$ compounds based upon CASSCF molecular orbital calculations and extended to the other 4f-block metal bipyridine compounds. The multireference molecular calculations better account for the experimentally determined properties of the molecules such as bond lengths and magnetic properties than do Lewis structures or properties derived from single reference DFT calculations. The multiconfigurational model developed for the $\mathrm{f}^{0}, \mathrm{f}^{14}(\mathrm{La}, \mathrm{Lu})$ and $\mathrm{f}^{1}, \mathrm{f}^{13}(\mathrm{Ce}, \mathrm{Yb})$ metals is extended to the intervening lanthanide metal compounds and is, accordingly, generally applicable for understanding the magnetic properties of the $4 \mathrm{f}$-block metal compounds. 


\section{RESULTS.}

Synthesis. As mentioned in the introduction, the $\mathrm{M}\left(\kappa^{2}-\text { bipy }\right)_{4}$ complexes of $\mathrm{La}$ to $\mathrm{Lu}$ are known. Some of the reported syntheses use $\mathrm{MX}_{3}(\text { thf })_{\mathrm{n}}, \mathrm{X}=\mathrm{Br}$ or I as the metal starting material, which is problematic since the bipyridine compounds are sparingly soluble in thf, as are the metal halides and the LiX by-products. An alternative synthesis that begins with a thf soluble source of $\mathrm{MX}_{3}$ and $\mathrm{LiX}$ in which the bipyridine compounds are insoluble is desirable. Ideally, the $\mathrm{M}\left(\kappa^{2} \text {-bipy }\right)_{4}$ compounds should crystallize from the mother liquor since their insolubility precludes recrystallization. Minimizing manipulation of sparingly soluble compounds is crucial for obtaining pure compounds that are used for physical property measurements.

Our strategy is to use the substituted cyclopentadienyl metal compounds that are soluble in thf as are the Li-containing byproducts. The cyclopentadienyl compounds that are used are $\left[1,3-\left(\mathrm{Me}_{3} \mathrm{Si}_{2}\right)_{2} \mathrm{C}_{5} \mathrm{H}_{3}\right]_{\mathrm{n}} \mathrm{M}$, where $\mathrm{M}$ is a lanthanide and $\mathrm{n}=3$ and the byproduct when $\mathrm{M}$ is $\mathrm{Li}$ and $n=1$ since both are readily soluble in thf. In the synthesis of $\mathrm{Tb}\left(\kappa^{2}-\text { bipy }\right)_{4},\left[\mathrm{C}_{5} \mathrm{H}_{4} \mathrm{Me}\right]_{\mathrm{n}} \mathrm{Tb}$, is used. The general equation for the reaction is illustrated in eq. 1 for $\left.\left[\left(\mathrm{Me}_{3} \mathrm{Si}\right)_{2} \mathrm{C}_{5} \mathrm{H}_{3}\right)\right]_{3} \mathrm{M}$.

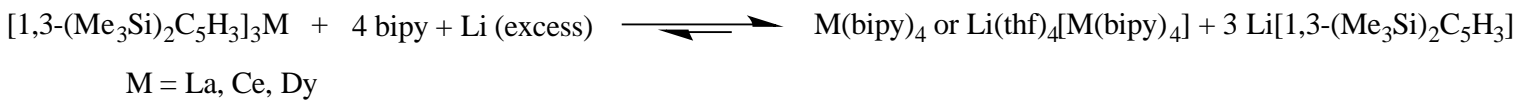

The synthetic protocol involves adding lithium metal wire to a solution of the cyclopentadienyl compound and bipyridine dissolved in thf. The synthesis details that are crucial for obtaining crystalline compounds of $\mathrm{M}\left(\kappa^{2}-\text { bipy }\right)_{4} \mathrm{M}=\mathrm{La}, \mathrm{Ce}$ and $\left[\mathrm{Li}(\operatorname{thf})_{4}\right]\left[\mathrm{M}\left(\kappa^{2}-\right.\right.$ bipy $\left.)_{4}\right], M=\mathrm{Tb}$, Dy are presented in the Experimental Section and Supporting Information.

The $\mathrm{La}\left(\kappa^{2} \text {-bipy }\right)_{4}($ thf $) \mathrm{x}, \mathrm{x}=1$ is obtained in $55 \%$ yield as black needles from the mother liquor. The crystals do not melt to $340{ }^{\circ} \mathrm{C}$ and do not re-dissolve in thf. When the thf solvent 
is replaced by diethyl ether, the base-free compounds when $\mathrm{x}=0$, are obtained as black needles in low (16\%) yield. The crystals obtained in $\mathrm{Et}_{2} \mathrm{O}$ are used for the X-ray crystallographic study. Combustion elemental analysis when $\mathrm{x}=1$ gives low (by $1.2 \%$ ) carbon analysis but the base-free compound gives excellent agreement with the calculated values. The cerium analogues, $\mathrm{Ce}\left(\kappa^{2} \text {-bipy }\right)_{4}(\mathrm{thf}) \mathrm{x}, \mathrm{x}=1$ or 2 , are obtained similarly as black needles in $47 \%$ and $36 \%$ yield, respectively. The values of $\mathrm{x}$ depends on the temperature at which the synthesis is conducted. The base-free compound is obtained as black needles when the metal source is $\mathrm{CeI}_{3}(\mathrm{thf})_{3}$, and these crystals are used for the X-ray crystallographic study.

The terbium anion $\left[\mathrm{Li}(\text { thf })_{4}\right]\left[\mathrm{Tb}\left(\kappa^{2} \text {-bipy }\right)_{4}\right]$ is prepared using $\left(\mathrm{C}_{5} \mathrm{H}_{4} \mathrm{Me}\right)_{3} \mathrm{~Tb}$ in low yield $(9 \%)$ and isolated as black needles from thf. The dysprosium anion $\left[\operatorname{Li}(\operatorname{thf})_{4}\right]\left[\mathrm{Tb}\left(\kappa^{2}-\text { bipy }\right)_{4}\right]$ is obtained from $\left[1,3-\left(\mathrm{Me}_{3} \mathrm{Si}\right)_{2} \mathrm{C}_{5} \mathrm{H}_{3}\right]_{3} \mathrm{Dy}$ in $60 \%$ yield from the mother liquor as black needles. Although both of the ion-pair compounds are sparingly soluble in thf, they dissolve in pyridine- $\mathrm{d}_{5}$ to give red solutions whose ${ }^{1} \mathrm{H}$ NMR spectra contains resonances due to free thf and four broad resonances attributed to the coordinated bipy ligands (see Experimental section for details).

The solid-state IR spectra of neutral bipyridine compounds provide a qualitative criterion to distinguish between $[\text { bipy }]^{\mathrm{x}}$, where $\mathrm{x}=0,-1$, or $-2 \cdot{ }^{9-10}$ In general, coordinated bipy ${ }^{0}$ has a strong absorption due to the $\mathrm{C}=\mathrm{C}$ and $\mathrm{C}=\mathrm{N}$ stretching modes in the region of $1610-1600 \mathrm{~cm}^{-1}$; bipy $^{(-1)}$, referred to as bipy radical anion, has several absorptions in the region of $1545-1490$ $\mathrm{cm}^{-1}$, while bipy ${ }^{(-2)}$, or bipy dianion, has two absorptions in the region of $1590-1560 \mathrm{~cm}^{-1}$. In addition, absorptions due to ring deformation motion appear in the region of $1090-900 \mathrm{~cm}^{-1}$ for bipy ${ }^{(-1)}$ and $870-800 \mathrm{~cm}^{-1}$ for bipy ${ }^{(-2)}$ while bipy ${ }^{0}$ is silent in this region. The IR spectra for the four compounds prepared in this article in the $1600-900 \mathrm{~cm}^{-1}$ region are listed in Table 1. 
Table 1. Solid-state IR stretching frequencies.

\begin{tabular}{llccc}
\hline & \multicolumn{3}{c}{$1625-1475 \mathrm{~cm}^{-1}$} & $1000-900 \mathrm{~cm}^{-1}$ \\
\hline $\mathrm{La}$ & $1529, \mathrm{~m}$ & $1503, \mathrm{~m}$ & $1487, \mathrm{~s}$ & $939, \mathrm{~s}$ \\
$\mathrm{Ce}$ & $1530, \mathrm{~m}$ & $1505, \mathrm{~m}$ & $1487, \mathrm{~s}$ & $946, \mathrm{~s}$ \\
$\mathrm{~Tb}$ & $1536, \mathrm{~m}$ & $1509, \mathrm{~m}$ & $1485, \mathrm{~s}$ & $946, \mathrm{~s}$ \\
$\mathrm{Dy}$ & $1568, \mathrm{~m}$ & $1536, \mathrm{~m}$ & $1485, \mathrm{~s}$ & $945, \mathrm{~s}$ \\
\hline
\end{tabular}

The IR features are in better agreement with the presence of bipyridine ligands with radicalanion character. The visible absorption spectra also contain signatures of radical anions for $\mathrm{M}$ $=\mathrm{Yb}$ and Dy (Figure 1). ${ }^{11-12}$ The other bipy compounds prepared in this work are not soluble enough in thf to give satisfactory absorption spectra. The $\mathrm{Yb}\left(\kappa^{2} \text {-bipy }\right)_{4}$ complex used was prepared by the literature method..$^{5}$

Thus, the bipy ${ }^{(-1)}$ ligands are clearly identified with the last two methods but not the bipy ${ }^{(-2)}$ and the bipy ${ }^{0}$. However, a formulae with four bipy ${ }^{(-1)}$ in the neutral $M\left(\kappa^{2}-\text { bipy }\right)_{4}$ complexes is unlikely because of the maximum oxidation state of + III for most lanthanides complexes.

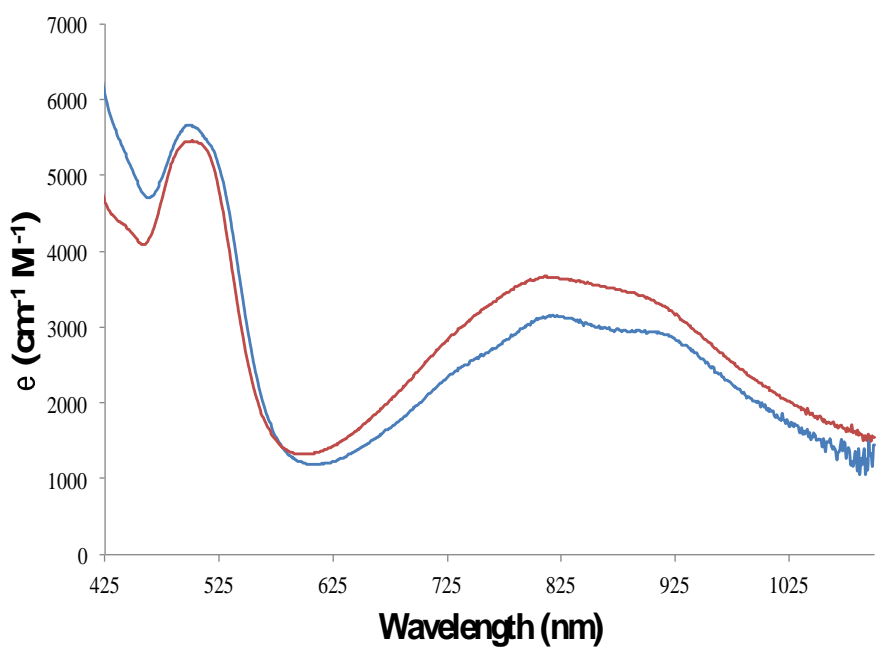

Figure 1. Visible absorption spectrum for $\left[\mathrm{Li}(\operatorname{thf})_{4}\right]\left[\mathrm{Dy}\left(\kappa^{2}-\text { bipy }\right)_{4}\right]$ (blue line) and $\mathrm{Yb}\left(\kappa^{2}-\right.$ bipy) ${ }_{4}^{5}$ (red line) in thf. 
Hydrolysis. In order to substantiate that thf is (or is not) present in the crystallized compounds, the compounds were suspended in $\mathrm{C}_{6} \mathrm{D}_{6}$ and hydrolyzed with $\mathrm{D}_{2} \mathrm{O}$, the $\mathrm{C}_{6} \mathrm{D}_{6}$ extracts separated from the precipitate and the solutions examined by ${ }^{1} \mathrm{H}$ NMR spectroscopy. The deutorolysis reactions are relatively slow and the samples are monitored until the relative ratios for the observed resonances are constant, up to $24 \mathrm{~h}$ in some cases.

The ${ }^{1} \mathrm{H}$ NMR spectra of the hydrolysate show the presence of three sets of resonances due to i) free thf at $\delta \mathrm{H}=3.57$ and $1.41 \mathrm{ppm}$ and ii) free bipyridine at 8.73 (ddd), 8.56 (ddd), 7.21 (dd) and $6.68(\mathrm{dd}) \mathrm{ppm}$, in agreement with the literature values. ${ }^{13-14}$ In addition the spectra contain a third set of multiplets (iii) whose chemical shifts range from $\delta \mathrm{H}=8.3$ to $3.2 \mathrm{ppm}$ due to a single $\mathrm{H}$ each; these are referred to as bipyD $\mathrm{D}_{2}$ resonances that are due to either the ortho- or para-dideuterobipyridine isomers, labeled A or B in Figure 2 that result from hydrolysis of the bipyridine radical anions. ${ }^{15}$ The eight multiplets are consistent with a single isomer of Cs symmetry, in which the four deshielded resonances at 8.27 (ddd), 7.18(dd), 6.97 (ddd), and 6.52 (ddd) are attributed to the 2-pyridyl ring hydrogen atoms and the four shielded resonances at 5.91 (ddd), 5.03 (ddd), 4.37 (ddd), and 3.12 (broad) are assigned to the azacyclohexadienyl group. Examination of the ${ }^{2} \mathrm{H}$ NMR spectrum resulting from the deuterolysis of $\mathrm{Ce}\left(\kappa^{2} \text {-bipy }\right)_{4}$ shows a resonance $\delta \mathrm{D}=3.12$ as a doublet, ${ }^{1} \mathrm{~J}_{\mathrm{HD}}=2 \mathrm{~Hz}$, associated with a gem-CHD group. In presence of $\mathrm{D}_{2} \mathrm{O}$, the $\mathrm{N}-\mathrm{D}$ resonance is not observed due to exchange with the $\mathrm{D}_{2} \mathrm{O}$. A computer-simulated spectrum suggests that the para- isomer (B) is the correct isomer (SI). 


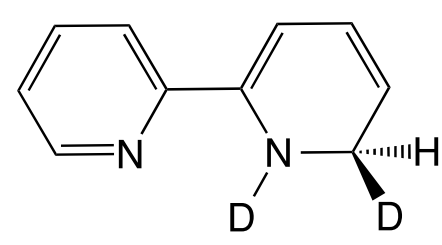

A

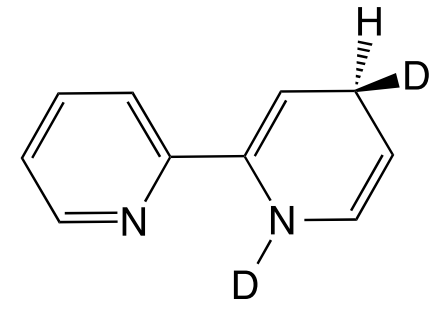

B

Figure 2. Representation of the two bipy $\mathrm{D}_{2}$ isomers.

The three sets of resonances observed on deuterolysis of $\mathrm{M}\left(\kappa^{2}-\mathrm{bipy}\right)_{4}, \mathrm{M}=\mathrm{La}, \mathrm{Ce}$ and $\left[\operatorname{Li}(\text { thf })_{4}\right]\left[\mathrm{Tb}\left(\kappa^{2} \text {-bipy }\right)_{4}\right]$ have different relative amounts of the individual components. For $\mathrm{M}$ $=\mathrm{La}$, the ratio of the total bipy to thf resonances is $28: 8.4$ or $4: 1.2$, which is in reasonable agreement for $\mathrm{La}\left(\kappa^{2}-\text { bipy }\right)_{4}($ thf $)$. The ratio of the free bipy to bipyD $\mathrm{D}_{2}$ resonances is $3.1: 1$. For $\mathrm{M}=\mathrm{Ce}$, the ratio of total bipy to thf resonances is $32: 16$ or $4: 2$, in good agreement with $\mathrm{Ce}\left(\kappa^{2} \text {-bipy }\right)_{4}(\mathrm{thf})_{2}$, and the ratio of free bipy to bipyD $\mathrm{D}_{2}$ is $3.0: 1$. For the $\mathrm{Tb}$ anion, the ratio of total bipy to thf resonances is $3.3: 4$ in reasonable agreement with the stoichiometry $\left[\mathrm{Li}(\mathrm{thf})_{4}\right]\left[\mathrm{Tb}\left(\kappa^{2} \text {-bipy }\right)_{4}\right]$, however, the ratio of free bipy to bipy $\mathrm{D}_{2}$ is $1.8: 1$, which is somewhat lower than found in the neutral compounds. In the latter hydrolysis, a white precipitate forms that may contain some of the liberated bipy ligands.

The origin of bipy $\mathrm{D}_{2}$ is developed from a review of the electrochemistry of bipyridine radical anions in various solvents. ${ }^{15}$ The first reduction of bipyridine (eq. 2) has $E_{1 / 2}=-2.1 \mathrm{~V}$ (vs. SCE). The second reduction (eq. 3) has $\mathrm{E}_{1 / 2}<-2.2 \mathrm{~V}$ (vs. SCE), indicating that net formation of bipy $^{(-2)}$ is less favorable.

$$
\begin{aligned}
& \text { bipy }+1 \mathrm{e}^{-} \longrightarrow \text { bipy }^{\bullet-} \quad \mathrm{E}_{1 / 2}=-2.1 \mathrm{~V} \\
& \text { bipy }+-1 \mathrm{e}^{-} \longrightarrow \text { bipy }{ }^{2-} \quad \mathrm{E}_{1 / 2}<-2.2 \mathrm{~V} \\
& 2 \text { bipy }{ }^{\bullet-} \longrightarrow \text { bipy }+ \text { bipy }^{2-} \\
& \text { bipy }^{2-}+2 \mathrm{H}^{+} \longrightarrow \text { bipyH }_{2}
\end{aligned}
$$


However, the dismutation of bipyH $^{\bullet}$ formed by protonation of bipy ${ }^{(-1)}$, eq. 6 , is favorable since the equilibrium constant is estimated to be greater than $10^{29}$, eq. 7 . Thus the formation of bipy and bipy $\mathrm{D}_{2}$ from deuterolysis of the metal compounds, in which bipy is present as a radical anion, is expected. This implies that the formation of bipy $\mathrm{D}_{2}$ and free bipy does not come necessarily from bipy ${ }^{(-2)}$ or bipy $^{0}$ but is favored by dismutation when bipy ${ }^{(-1)}$ ligands are present as radical anions.

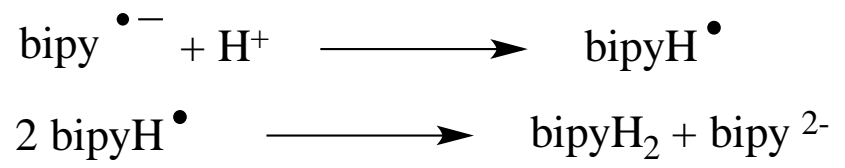

Assuming the net hydrolysis reaction of $\mathrm{M}\left(\kappa^{2}-\text { bipy }\right)_{4}$, in which three ligands are radical anions, is indicated as shown in eq. 8 , and using the dismutation reaction in eq. 7 , the ratio of bipy to bipy $\mathrm{D}_{2}$ should be 1.67:1 (eq. 9). As noted above, the experimental value for the neutral molecules is about $3: 1$ and that for the anion is $1.8: 1$. While the latter ratio is in good agreement with the expected ratio, the former ratio indicates that more bipy ${ }^{(0)}$ is formed on hydrolysis. The solid-state crystal structures and the CASSCF molecular orbital computational results described in the following sections indicate a possible reason for these different hydrolysis results since the initial compounds that are formed can undergo redistribution reactions.

$$
\begin{aligned}
& \mathrm{M}(\text { bipy })_{4}+3 \mathrm{D}_{2} \mathrm{O} \longrightarrow \mathrm{M}(\mathrm{OD})_{3}+3 \text { bipyD }^{\bullet}+\text { bipy } \\
& 3 \text { bipyD }^{\bullet}+\text { bipy } \longrightarrow 5 / 2 \text { bipy }+3 /{ }_{2} \text { bipyD }_{2}
\end{aligned}
$$

X-ray crystal structures. $\mathbf{M}\left(\kappa^{2}-\text { bipy }\right)_{4}(\text { thf })_{x}, M=L a$, Ce. Both of these neutral molecules crystallize in the monoclinic crystal system in space group $C_{2 / c}$. ORTEPs with the atom numbering scheme are shown in Figure 4 and S1-3. Some significant bond distances are listed in Table 2 and a complete list of bond distances and angles is available in the 
Supporting Information (S1-15) as are the crystal data and crystallographic solutions. The atom-numbering schemes are different for the isomorphous and isostructural molecules due to the choice of the $\mathrm{C}_{2}$ axis, see Figure 3. In each molecule, the four bipyridine ligands are bidentate and the nitrogen atoms occupy the corners of a cube and therefore are classified as $\kappa^{2}$-bipy (see shape parameters in Discussion Section below). The M-N distances are arranged in two distinct pairs containing two bidentate bipy ligands in each compound, one pair with shorter average M-N distances than those in the other pair; these pairs are labeled ring 1 and ring 2, respectively, and the individual distances in the bipyridine ligands are labeled as indicated in the graphic associated with Table 2.
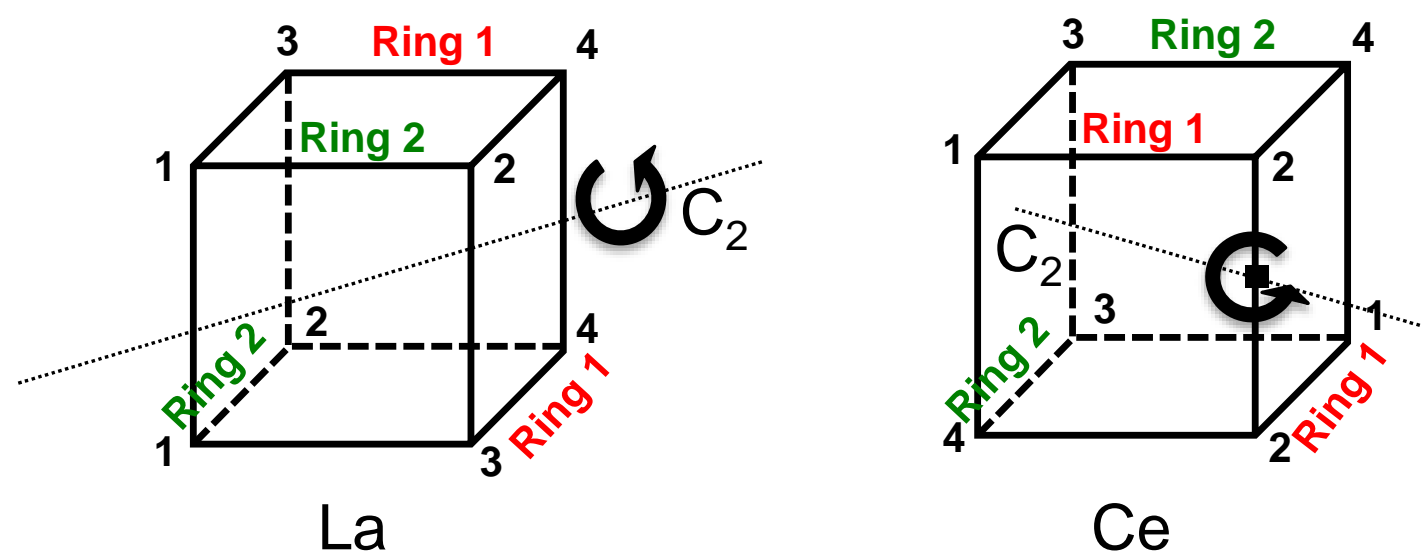

Figure 3. Representation of the ring 1 and ring 2, showing the orientation of the $\mathrm{C}_{2}$ axis. 

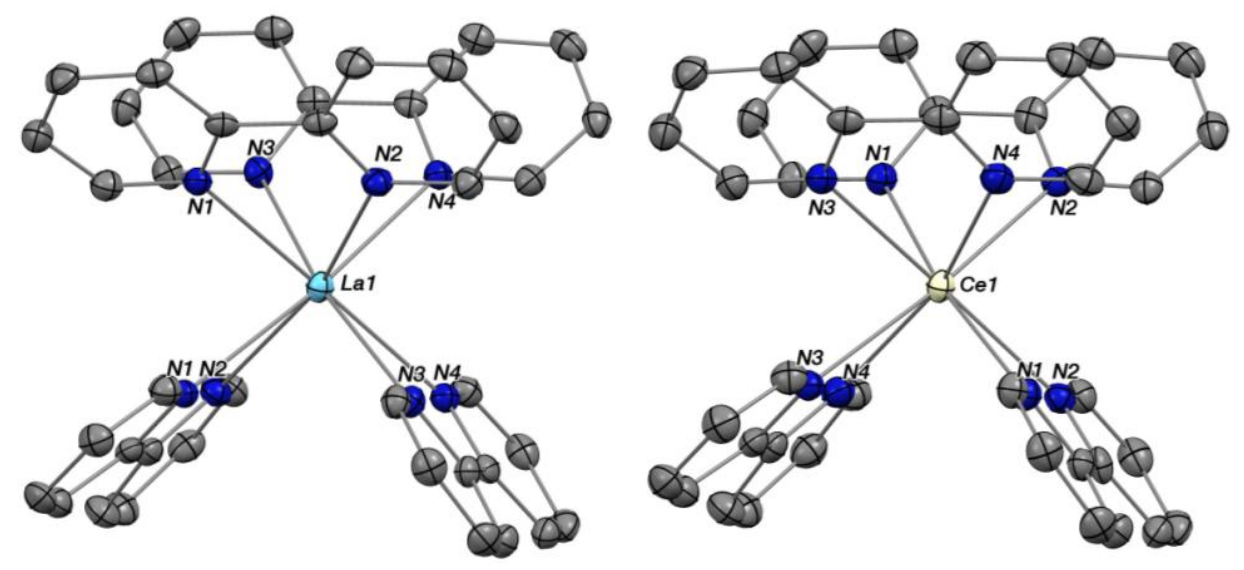

Figure 4. ORTEPs of $\mathrm{M}\left(\kappa^{2}-\text { bipy }\right)_{4}, \mathrm{M}=\mathrm{La}, \mathrm{Ce}$. Thermal ellipsoids are at $50 \%$ probability. Carbon atoms are in grey, nitrogen atoms in blue, lanthanum in light blue and cerium in light yellow. The views are guiding the eyes for ring 1 and ring 2 assignments. 
Table 2. Bond distances $(\AA)$ in $\mathrm{M}\left(\kappa^{2} \text {-bipy }\right)_{4}$ and labeling scheme for the 2,2'-bipyridine ligand.

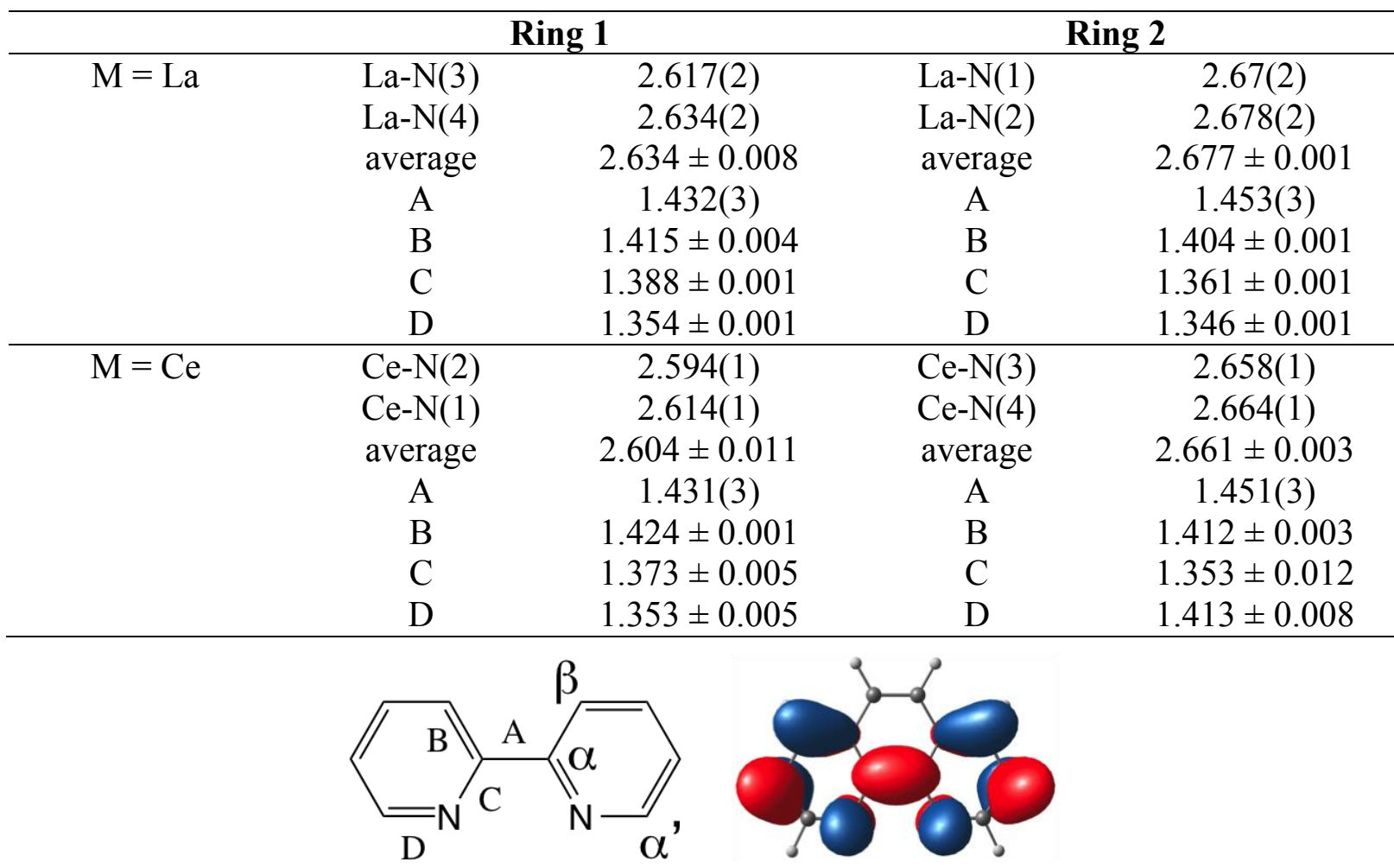

The bond distance trends for equivalent bonds in the two structures are similar. La-N distances are longer than those for Ce-N by $0.012 \AA$, as expected. The average La-N distance associated with ring 1 is $0.051 \AA$ shorter than that associated with ring 2 ; for cerium, the difference is $0.057 \AA$. The atom pair distances (for $\mathrm{M}=\mathrm{La}$ ), labeled $\mathrm{A}$ in ring 1 are shorter than that in ring 2 by $0.021 \AA$ while those labeled B, C and D are longer in ring 1 by 0.011 , 0.027 and $0.008 \AA$, respectively, than those associated with ring 2 . For cerium, a similar trend is observed with $\mathrm{A}$ in ring 1 , shorter by $0.020 \AA$ while those in $\mathrm{B}, \mathrm{C}$, and $\mathrm{D}$ are longer by $0.012,0.020$, and $0.012 \AA$, respectively, in ring 2 .

The bond lengths in the atom pairs labeled A, B, C, and D follow the pattern observed in the crystal structures of free bipyridine ${ }^{16}$ and in $\mathrm{K}\left(2,2^{\prime}\right.$-bipy)(en) and $\mathrm{Rb}_{2}\left(2,2^{\prime}\right.$-bipy)(en), ${ }^{10}$; the 
latter two are associated with examples of a radical anion and a dianion, respectively, as shown in Table 3.

Table 3. Bond lengths $(\AA)$ for bipy ${ }^{0}$, bipy ${ }^{(-1)}$, and bipy ${ }^{(-2)}$.

\begin{tabular}{cccc}
\hline & 2,2'-bipy & 2,2'-bipy & 2,2'-bipy $^{(-2)}$ \\
\hline A & $1.490(3)$ & $1.431(3)$ & $1.399(6)$ \\
B & $1.394(2)$ & $1.427 \pm 0.01$ & $1.452(4)$ \\
C & $1.346(2)$ & $1.389 \pm 0.01$ & $1.436(4)$ \\
D & $1.341(2)$ & $1.377 \pm 0.01$ & $1.343(4)$ \\
\hline
\end{tabular}

Inspection of the distances labeled $\mathrm{A}, \mathrm{B}, \mathrm{C}$ and $\mathrm{D}$ in Table 3 in ring 1 in the La and Ce compounds clearly shows that both of these rings contain bipyridine ligands that are classified as radical anions rather than neutral or dianionic bipyridine ligands. However, these distances need to be taken cautiously since the crystallographic symmetry imposes an average on two pairs of bipy ligands. It means that the average electronic structure of the bipyridine ligands is close to bipy ${ }^{(-1)}$.

It is also clear that the distances labeled A, B, C, and D in ring 2 (Table 4) are very close to the mean value of these distances in $2,2^{\prime}$-bipy plus $2,2^{\prime}$-bipy ${ }^{(-1)}$, which classify each bipy as 2,2'-bipy ${ }^{(-1 / 2)}$. Therefore, the four bipy ligands in the $\mathrm{M}\left(\kappa^{2}-\text { bipy }\right)_{4}, \mathrm{M}=\mathrm{La}$, Ce carry a net -3 charge, which by implication identifies the oxidation number of the metal as +3 . The $\mathrm{M}-\mathrm{N}$ distances also follow this trend since those in ring 1 are shorter than those in ring 2 by about $0.05 \AA$ in each compound. The bond distance trends support the deductions from the IR and $\mathrm{L}_{\mathrm{III}}$-edge XANES datum for Ce as well as the hydrolysis experiments. It will be discussed below.

The solid-state structures of $\mathrm{M}\left(\kappa^{2}-\text { bipy }\right)_{4}, \mathrm{M}=\mathrm{La}, \mathrm{Ce}$ form a polymeric chain, which presumably accounts for their insolubility and lack of volatility. A simplified ORTEP for the packing is shown in Figure 5. For $\mathrm{M}=\mathrm{La}$, the short intermolecular contacts are associated 
with the rings labeled 2, each of which are classified as bipy ${ }^{(-1 / 2)}$ since the A distances in ring 2 are midway between those of bipy ${ }^{(0)}$ and bipy $^{(-1)}$ and are colored green. The intermolecular Carbon-p $\pi .$. Carbon-p $\pi$ contact distance between $\mathrm{C} \alpha$ and $\mathrm{C} \beta$ (Table 2) on the rings labeled 2 on adjacent cerium molecules is $3.24 \AA$ and the intermolecular Carbon-p $\pi$...Carbon-p $\pi$ contact distances between $\mathrm{C} \alpha$ '...C $\alpha$ ' is slightly longer in the cerium molecules at $3.32 \AA$.

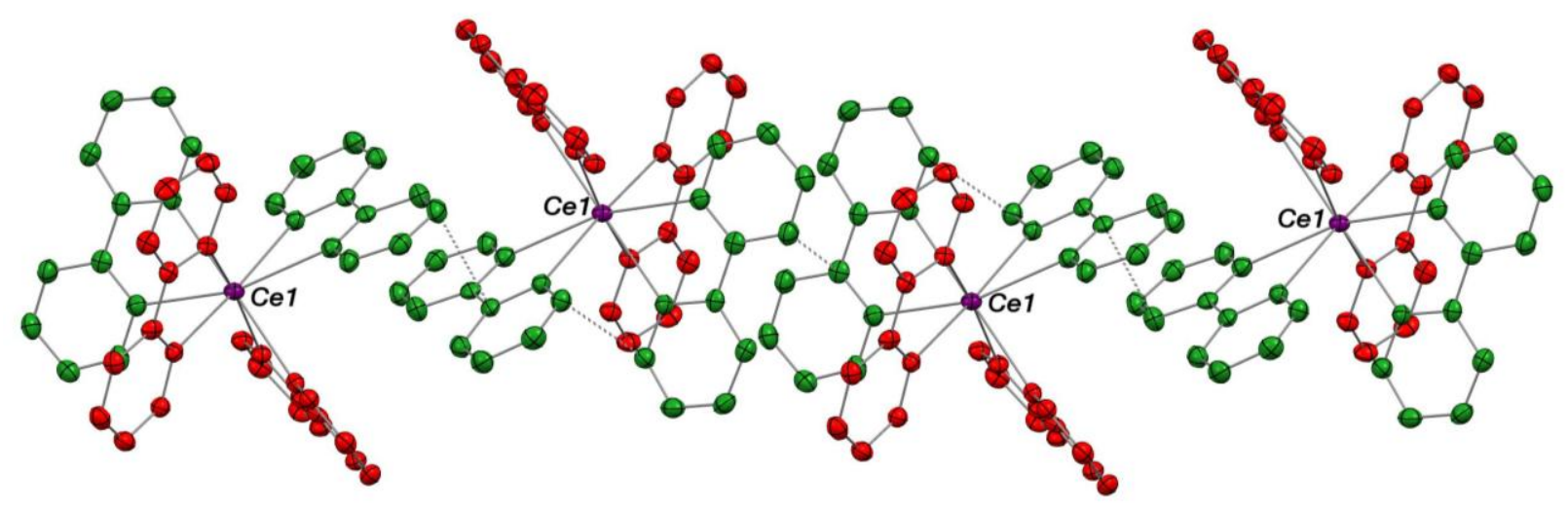

Figure 5. Packing diagram for $\mathrm{Ce}(\text { bipy })_{4}$. Thermal ellipsoids are at $50 \%$ probability. Rings 1 and 2 are shown in red and green, respectively. Short distances along the polymeric chain are marked in dashed grey lines.

The terbium anion also crystallizes in the monoclinic crystal system but in space group $\mathrm{P}_{21 / \mathrm{c}}$ in which the $\left[\mathrm{Li}(\mathrm{thf})_{4}\right]$ cations are separated from the $\left[\mathrm{M}\left(\kappa^{2} \text {-bipy }\right)_{4}\right]$ anions and there are no short intermolecular contacts between the anions in the crystal. An ORTEP is shown in Figure 6; some bond distances are shown in Table 5 and all distances and angles are available in SI as are the crystal data and structure solution information. The geometry of the eightcoordinate anion is quite irregular as shown by the shape parameters (see discussion section). The average $\mathrm{Tb}-\mathrm{N}$ distance is $2.499 \pm 0.013 \AA$; the individual $\mathrm{Tb}-\mathrm{N}$ distances do not seem to follow a recognizable pattern as in the neutral compounds. The distances labeled A, B, C, and $\mathrm{D}$ follow a different pattern than those in the neural compounds since they are identical in all four $\kappa^{2}$-bipy ligands and close to those in the bipy radical $2,2^{\prime}$-bipy ${ }^{(-1)}$. Thus the average A, 
$\mathrm{B}, \mathrm{C}$, and $\mathrm{D}$ distances in the bipy ligands are $1.425 \pm 0.002 \AA, 1.419 \pm 0.003 \AA, 1.389 \pm$ $0.003 \AA$ and $1.353 \pm 0.003 \AA$, respectively.

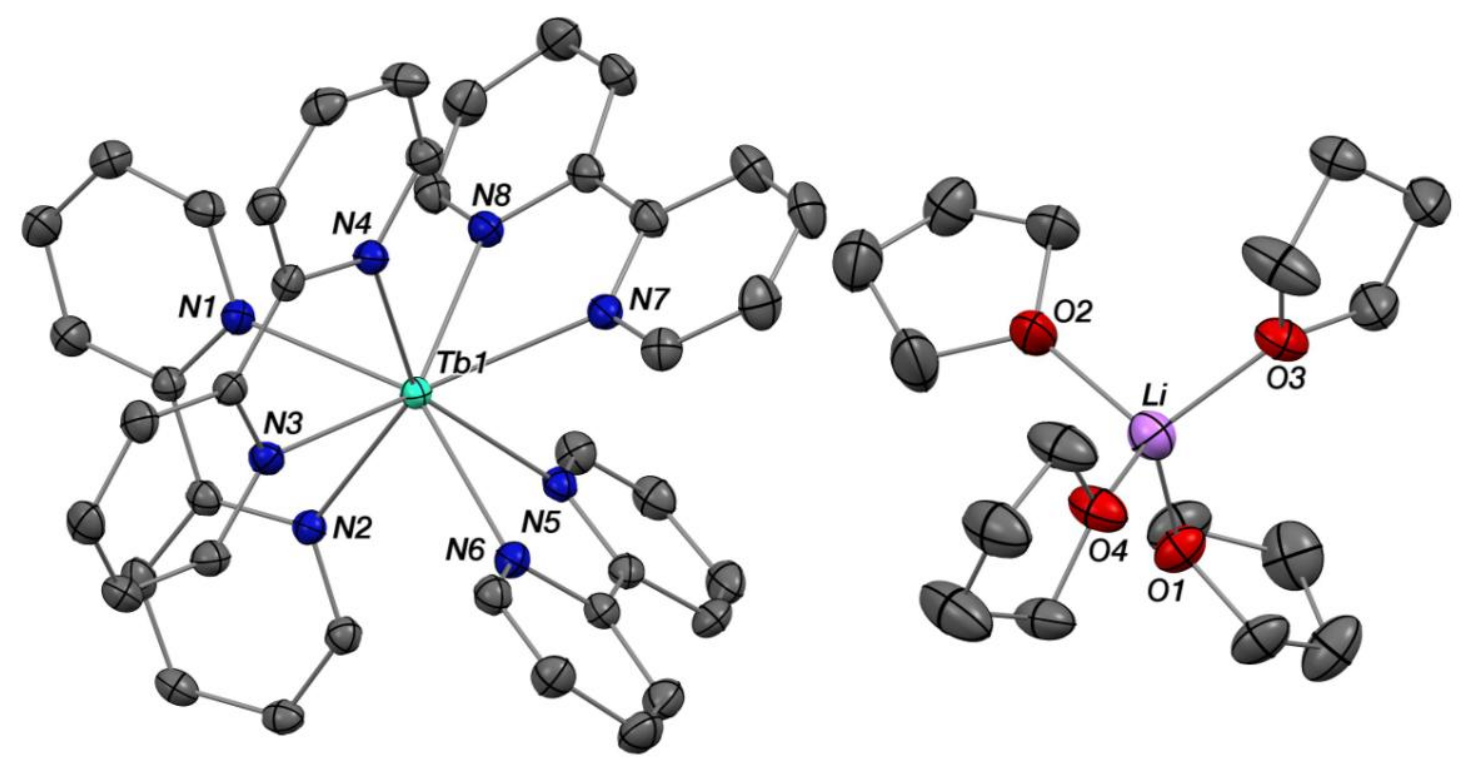

Figure 6. ORTEP of $\left[\mathrm{Li}(\mathrm{thf})_{4}\right]\left[\mathrm{M}\left(\kappa^{2} \text {-bipy }\right)_{4}\right]$ Thermal ellipsoids are at $50 \%$ probability. Carbon atoms are in grey, nitrogen atoms in blue, oxygen atoms in red, terbium in light green and lithium in purple. 
Table 4. Selected bond distances $(\AA)$ for $\left[\mathrm{M}\left(\kappa^{2}-\text { bipy }\right)_{4}\right]$.

\begin{tabular}{|c|c|c|c|c|c|c|c|c|c|c|c|c|}
\hline & \multicolumn{2}{|c|}{$\mathrm{La}^{(\mathrm{a})}$} & \multicolumn{2}{|c|}{$\mathrm{Ce}^{(\mathrm{a})}$} & \multicolumn{2}{|c|}{$\mathrm{Sm}^{(b)}$} & \multicolumn{2}{|c|}{$\mathrm{Eu}^{(\mathrm{b})}$} & \multicolumn{2}{|c|}{$\mathrm{Yb}^{(\mathrm{b})}$} & \multicolumn{2}{|c|}{$\mathrm{Lu}^{(\mathrm{b})}$} \\
\hline & Ring 1 & Ring 2 & ng 1 & Ring 2 & ng 1 & Ring 2 & ng 1 & Ring 2 & ng 1 & Ring 2 & ing 1 & Ring 2 \\
\hline $\begin{array}{l}\mathrm{M}- \\
\mathrm{N}\end{array}$ & $\begin{array}{c}2.626 \pm \\
0.008\end{array}$ & $\begin{array}{c}2.677 \pm \\
0.001\end{array}$ & $\begin{array}{c}2.604 \pm \\
0.011\end{array}$ & $\begin{array}{c}2.661 \pm \\
0.003\end{array}$ & $\begin{array}{c}2.548 \pm \\
0.009\end{array}$ & 0.002 & $\begin{array}{c}2.686 \pm \\
0.016\end{array}$ & & $\begin{array}{c}2.44 \pm \\
0.02\end{array}$ & $\begin{array}{c}2.54 \pm \\
0.02\end{array}$ & $\begin{array}{l}2.397 \pm \\
0.025\end{array}$ & 0.014 \\
\hline $\mathrm{A}^{(}$ & $1.432(3)$ & $1.452(3)$ & $1.431(3)$ & $1.451(3)$ & $1.425(6)$ & $1.433(4)$ & $1.417(7)$ & $1.484(7)$ & 1.41(1) & $1.48(1)$ & $1.42(1)$ & $1.47(1)$ \\
\hline $\mathrm{B}^{(\mathrm{c}}$ & $\begin{array}{c}1.415 \pm \\
0.004\end{array}$ & $\begin{array}{c}1.404 \pm \\
0.001\end{array}$ & $\begin{array}{c}1.424 \pm \\
0.001\end{array}$ & $\begin{array}{c}1.415 \pm \\
0.003\end{array}$ & $\begin{array}{c}1.373 \pm \\
0.006\end{array}$ & $\begin{array}{r}1.346 \\
0.004\end{array}$ & $\begin{array}{c}1.428 \pm \\
0.002\end{array}$ & $\begin{array}{c}1.388 \pm \\
0.002\end{array}$ & $\begin{array}{c}1.39 \pm \\
0.01\end{array}$ & $\begin{array}{c}1.36 \pm \\
0.01\end{array}$ & $\begin{array}{c}1.39 \pm \\
0.01\end{array}$ & $\begin{array}{c}1.35 \pm \\
0.01\end{array}$ \\
\hline $\mathrm{C}^{(\mathrm{c}}$ & $\begin{array}{c}1.388 \pm \\
0.001\end{array}$ & $\begin{array}{c}1.361 \pm \\
0.001\end{array}$ & $\begin{array}{c}1.381 \pm \\
0.005\end{array}$ & $\begin{array}{c}1.321 \pm \\
0.020\end{array}$ & $\begin{array}{c}1.373 \pm \\
0.006\end{array}$ & $\begin{array}{c}1.347 \pm \\
0.014\end{array}$ & $\begin{array}{c}1.380 \pm \\
0.001\end{array}$ & $\begin{array}{c}1.346 \pm \\
0.001\end{array}$ & $\begin{array}{c}1.39 \pm \\
0.01\end{array}$ & $\begin{array}{c}1.35 \pm \\
0.01\end{array}$ & $\begin{array}{c}1.39 \pm \\
0.01\end{array}$ & $\begin{array}{c}1.35 \pm \\
0.01\end{array}$ \\
\hline $\mathrm{D}^{(\mathrm{c}}$ & $\begin{array}{c}1.355 \pm \\
0.001\end{array}$ & $\begin{array}{c}1.353 \pm \\
0.008\end{array}$ & $\begin{array}{c}1.354 \pm \\
0.004\end{array}$ & $\begin{array}{c}1.342 \pm \\
0.007\end{array}$ & $\begin{array}{c}1.355 \pm \\
0.002\end{array}$ & $\begin{array}{c}1.343 \pm \\
0.010\end{array}$ & $\begin{array}{c}1.338 \pm \\
0.016\end{array}$ & $\begin{array}{c}1.325 \pm \\
0.002\end{array}$ & $\begin{array}{c}1.35 \pm \\
0.01\end{array}$ & $\begin{array}{c}1.35 \pm \\
0.01\end{array}$ & $\begin{array}{c}1.35 \pm \\
0.01\end{array}$ & $\begin{array}{c}1.35 \pm \\
0.01\end{array}$ \\
\hline
\end{tabular}

a) This work, b) ref 5 , c) see figure 4.

Table 5. Selected bond distances $(\AA)$ for $\left[\operatorname{Li}(\text { thf })_{4}\right]\left[\mathrm{M}\left(\kappa^{2}-\text { bipy }\right)_{4}\right]$.

\begin{tabular}{ccc}
\hline & $\mathrm{Tb}^{(\mathrm{a})}$ & $\mathrm{Lu}^{(\mathrm{b})}$ \\
\hline $\mathrm{M}-\mathrm{N}$ (average) & $2.499 \pm 0.013$ & $2.434 \pm 0.024$ \\
$\mathrm{~A}^{(\mathrm{c})}$ & $1.425 \pm 0.002$ & $1.41 \pm 0.01$ \\
$\mathrm{~B}^{(\mathrm{c})}$ & $1.419 \pm 0.003$ & $1.384 \pm 0.003$ \\
\hline
\end{tabular}

a) This work, b) ref 5, c) see figure 6 . 


\section{Magnetic susceptibility, $\mathrm{L}_{\mathrm{III}}$-XANES, and EPR Spectroscopy.}

The magnetic susceptibility for six compounds are shown as plots of $\chi$ and $\mu_{\text {eff }}$ as a function of the temperature in Figure 7 to Figure 10 and $\chi \mathrm{T}$ and $1 / \chi$ plots are available in SI (S10-15). The experimental values of $\chi \mathrm{T}$ and $\mu_{\mathrm{eff}}$ at $300 \mathrm{~K}$ are listed in Table 6. For $\left[\mathrm{M}\left(\kappa^{2}-\text { bipy }\right)_{4}\right] \mathrm{M}=$ $\mathrm{La}, \mathrm{Ce}$, the values of $\mu_{\text {eff }}$ decrease slightly from $300 \mathrm{~K}$ to about $50 \mathrm{~K}$ (La) and $150 \mathrm{~K}(\mathrm{Ce})$ then they decrease rapidly to $\approx 0.7 \mu_{\mathrm{B}}(\mathrm{La})$ and $1.2 \mu_{\mathrm{B}}(\mathrm{Ce})$ as the temperature approaches 5 $\mathrm{K}$. The shape of the plot for $\mathrm{M}=\mathrm{Yb}$ is similar although the slope is more gradual to $5 \mathrm{~K}$ where $\mu_{\text {eff }} \approx 2 \mu_{\mathrm{B}}$. The plot for $\mathrm{M}=\mathrm{Eu}$ is essentially flat to very low temperature and is similar to that for the anionic compounds of $\mathrm{Tb}$ and $\mathrm{Dy}$, except at very low temperature. The temperature dependence parallels the short intermolecular contact distances between $\mathrm{C} \alpha \ldots \mathrm{C} \beta$ in the neutral polymeric compounds that is most likely ascribed to extended antiferromagnetic coupling between the spins on rings labeled 2 and colored in green in Figure 5.

The expected magnetic moments are obtained by the sum of the $\chi \mathrm{T}$ values for the gas phase free-ion of a given metal and the possible values of the total spin (S) for three or four electrons distributed over the bipy ligands, that is, $\mathrm{S}$ can take the values of $0,1 / 2,1,3 / 2$, and 2 . These values, listed in Table 6, are determined under the following assumptions, i) the free ion value for the metal is due to a single electronic state, ii) the total spin is contributed by the number and orientation $(\alpha, \beta)$ of the three or four electrons in the bipy $\pi^{*}$-MOs, and iii) the total spin is the sum of these $\chi \mathrm{T}$ values. Under these assumptions, two patterns emerge on inspection of Table 6: i) the experimental values for $\chi \mathrm{T}\left(\mu_{\text {eff }}\right)$ fall in the range of the expected values for $\mathrm{S}=0$ and $1 / 2$ in $\mathrm{M}\left(\kappa^{2} \text {-bipy }\right)_{4}$ for the trivalent metals $\mathrm{La}, \mathrm{Ce}, \mathrm{Yb}$ and divalent $\mathrm{Eu}$ and ii) the experimental values for $\chi \mathrm{T}\left(\mu_{\mathrm{eff}}\right)$ fall in the range for $\mathrm{S}=3 / 2$ and $\mathrm{S}=2$ in $\left[\operatorname{Li}(\text { thf })_{4}\right]\left[\mathrm{M}\left(\kappa^{2}-\text { bipy }\right)_{4}\right]$ for $\mathrm{M}=\mathrm{Tb}$ and Dy. These empirical patterns are augmented and 
illuminated by the multireference quantum mechanical calculations described below for La, $\mathrm{Ce}$, and $\mathrm{Yb}$ that have two sets of M-N and A distances in the crystal structures of $\mathrm{La}, \mathrm{Ce}, \mathrm{Eu}$, and $\mathrm{Yb}$. Although no calculation were attempted for $\mathrm{Tb}$ and $\mathrm{Dy}$, the pattern established for the neutral molecules is validated by the eight identical $\mathrm{M}-\mathrm{N}$ and four A distances in the crystal structure of $\mathrm{Tb}$.
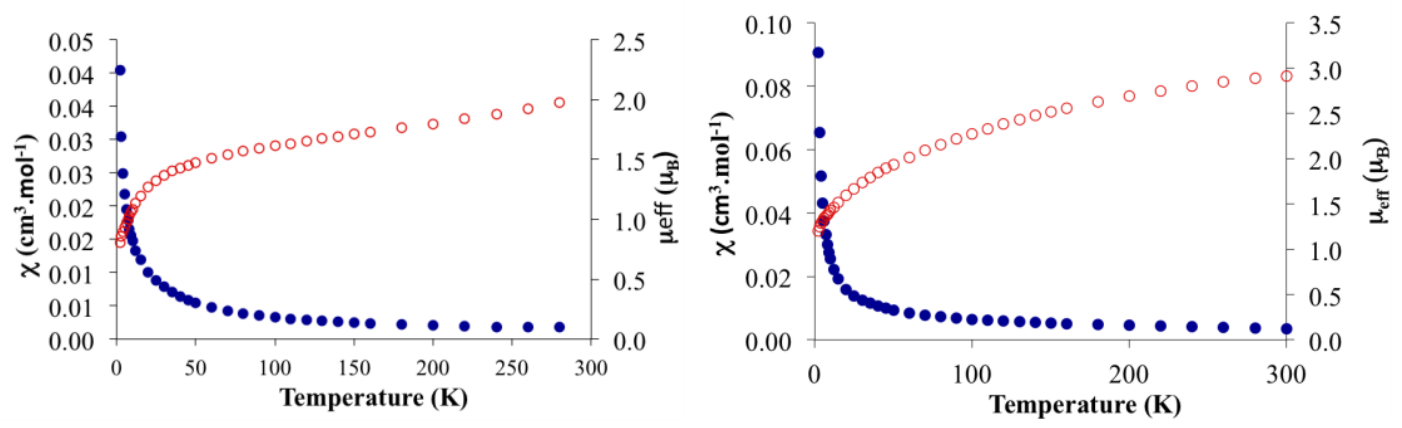

Figure 7. Temperature dependent magnetic data for $\left[\mathrm{La}\left(\kappa^{2}-\text { bipy }\right)_{4}\right]($ left $)$ and for $\left[\mathrm{Ce}\left(\kappa^{2}-\right.\right.$ bipy $)_{4}$ (right). Red unfilled dots are for the $\mu_{\text {eff }}$ plot and blue filled dot for $\chi$.
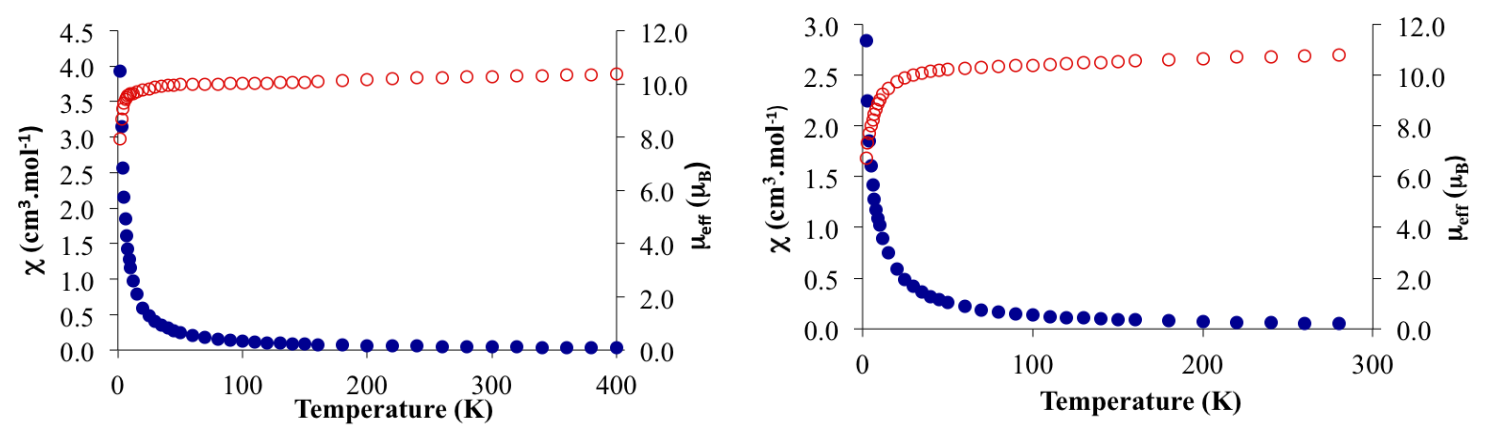

Figure 8. Temperature dependent magnetic data for $\left[\operatorname{Li}(\operatorname{thf})_{4}\right]\left[\mathrm{Tb}\left(\kappa^{2}-\text { bipy }\right)_{4}\right]$ (left) and $\left[\operatorname{Li}(\text { thf })_{4}\right]\left[\right.$ Dy $\left.\left(\kappa^{2}-\text { bipy }\right)_{4}\right]$ (right). Red unfilled dots are for the $\mu_{\text {eff }}$ plot and blue filled dot for $\chi$. 

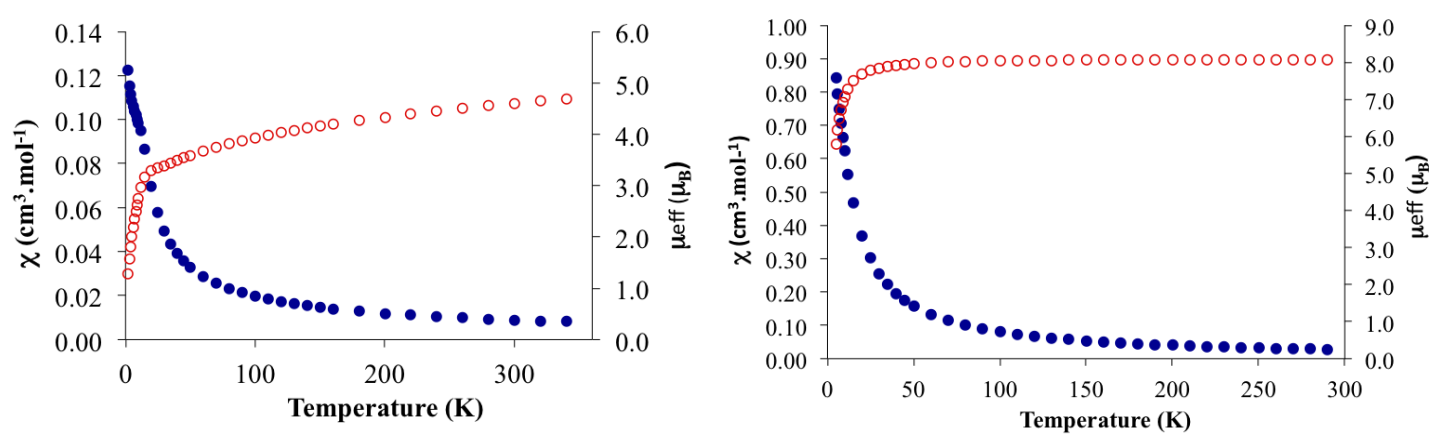

Figure 9. Temperature dependent magnetic data for $\left[\mathrm{Yb}\left(\kappa^{2}-\text { bipy }\right)_{4}\right]($ left $)$ and $\left[\mathrm{Eu}\left(\kappa^{2}-\text { bipy }\right)_{4}\right]$ (right). Red unfilled dots are for the $\mu_{\text {eff }}$ plot and blue filled dot for $\chi$.

Table 6. Expected $\chi \mathrm{T}$ values in $\mathrm{cm}^{3} \cdot \mathrm{K} \cdot \mathrm{mol}^{-1}$ for the various possible configurations. The values $\mu_{\text {eff }}$ in parentheses are in units of $\mu_{\mathrm{B}}$.

\begin{tabular}{|c|c|c|c|c|c|c|c|}
\hline \multirow[b]{2}{*}{ M } & \multirow[b]{2}{*}{$\begin{array}{c}\text { Term } \\
(\text { symbol })^{\mathrm{a})}\end{array}$} & \multirow[b]{2}{*}{$\begin{array}{c}\chi \mathrm{T} \\
\left(\mu_{\mathrm{eff}}\right)^{\mathrm{b})}\end{array}$} & \multicolumn{4}{|c|}{$\chi \mathrm{T}\left(\mu_{\mathrm{eff}}\right) \Sigma(\mathrm{M}+\square)$} & \multirow{2}{*}{$\begin{array}{r}\chi^{\mathrm{T}} \\
(\exp )\end{array}$} \\
\hline & & & $\mathrm{S}=1 / 2$ & $\mathrm{~S}=1$ & $\mathrm{~S}=3 / 2$ & $S=2$ & \\
\hline $\mathrm{La}^{\mathrm{III}}$ & ${ }^{1} \mathrm{~S}$ & 0 & $\begin{array}{c}0.37 \\
(1.73)\end{array}$ & $\begin{array}{c}0.74 \\
(2.43)\end{array}$ & $\begin{array}{l}1.11 \\
(2.98)\end{array}$ & $\begin{array}{c}1.48 \\
(3.44)\end{array}$ & $\begin{array}{c}0.49 \\
(1.98)\end{array}$ \\
\hline $\mathrm{Ce}^{\mathrm{III}}$ & ${ }^{2} \mathrm{~F}_{5 / 2}$ & $\begin{array}{c}0.80 \\
(2.53)\end{array}$ & $\begin{array}{c}1.17 \\
(3.06)\end{array}$ & $\begin{array}{c}1.57 \\
(3.54)\end{array}$ & $\begin{array}{c}1.91 \\
(3.91)\end{array}$ & $\begin{array}{c}2.28 \\
(4.27)\end{array}$ & $\begin{array}{c}1.07 \\
(2.93)\end{array}$ \\
\hline $\mathrm{Eu}^{\mathrm{II}}$ & ${ }^{8} \mathrm{~S}_{7 / 2}$ & $\begin{array}{c}7.88 \\
(7.94)\end{array}$ & $\begin{array}{c}8.25 \\
(8.12)\end{array}$ & $\begin{array}{c}8.62 \\
(8.30)\end{array}$ & $\begin{array}{c}8.99 \\
(8.48)\end{array}$ & $\begin{array}{c}9.36 \\
(8.65)\end{array}$ & $\begin{array}{c}8.12 \\
(8.06)\end{array}$ \\
\hline $\mathrm{Yb}^{\mathrm{III}}$ & ${ }^{2} \mathrm{~F}_{7 / 2}$ & $\begin{array}{c}2.59 \\
(4.55)\end{array}$ & $\begin{array}{c}2.96 \\
(4.87)\end{array}$ & $\begin{array}{c}3.33 \\
(5.16)\end{array}$ & $\begin{array}{c}3.70 \\
(5.44)\end{array}$ & $\begin{array}{c}4.07 \\
(5.71)\end{array}$ & $\begin{array}{c}2.65 \\
(4.60)\end{array}$ \\
\hline $\mathrm{Tb}^{\mathrm{III}}$ & ${ }^{7} \mathrm{~F}_{6}$ & $\begin{array}{l}11.80 \\
(9.72)\end{array}$ & $\begin{array}{l}12.17 \\
(9.87)\end{array}$ & $\begin{array}{c}12.57 \\
(10.02)\end{array}$ & $\begin{array}{c}12.91 \\
(10.16)\end{array}$ & $\begin{array}{c}13.28 \\
(10.31)\end{array}$ & $\begin{array}{c}13.8 \\
(10.5)\end{array}$ \\
\hline Dy ${ }^{\text {III }}$ & ${ }^{6} \mathrm{H}_{5 / 2}$ & $\begin{array}{l}14.10 \\
(10.6)\end{array}$ & $\begin{array}{c}14.47 \\
(10.76)\end{array}$ & $\begin{array}{c}14.84 \\
(10.90)\end{array}$ & $\begin{array}{c}15.21 \\
(11.03)\end{array}$ & $\begin{array}{c}15.58 \\
(11.16)\end{array}$ & $\begin{array}{c}15.1 \\
(11.0)\end{array}$ \\
\hline
\end{tabular}

a) gas phase free ion term symbol, b) $\chi \mathrm{T}$ in units of $\mathrm{cm}^{3} \cdot \mathrm{K} \cdot \mathrm{mol}^{-1}$ and $\mu_{\mathrm{eff}}$ in $\mu_{\mathrm{B}}$.

The Ln $\mathrm{L}_{\mathrm{III}}$-edge XANES for the Ce and $\mathrm{Yb} \kappa^{2}$-bipy 4 complexes are shown in Figure 10, together with data from $\mathrm{CeF}_{3} \mathrm{CeF}_{4}, \mathrm{Cp}_{2}{ }_{2} \mathrm{Yb}\left(\mathrm{Et}_{2} \mathrm{O}\right)$, and $\mathrm{Yb}_{2} \mathrm{O}_{3}$ for comparison. The $\mathrm{Ce}\left(\kappa^{2}-\right.$ 
bipy) ${ }_{4}$ spectrum shows a clear signature of a $\mathrm{Ce}(\mathrm{III})$ compound $^{17}$, with no indication of a feature at the position of the two main peaks in $\mathrm{CeO}_{2}$. Likewise, $\mathrm{Yb}\left(\kappa^{2}-\text { bipy }\right)_{4}$ is clearly predominantly $\mathrm{Yb}(\mathrm{III})$ : a $\mathrm{Yb}(\mathrm{II})$ signature feature would occur as a lower energy peak or shoulder near $8938 \mathrm{eV},{ }^{18}$ where the $\mathrm{Yb}\left(\kappa^{2} \text {-bipy }\right)_{4}$ and $\mathrm{Yb}_{2} \mathrm{O}_{3}$ data are nearly identical. No temperature dependence was observed between $30 \mathrm{~K}$ and $300 \mathrm{~K}$ for the Ce data nor between $30 \mathrm{~K}$ and $165 \mathrm{~K}$ for the $\mathrm{Yb}$ data (Figure $\mathrm{S} 16)$. 


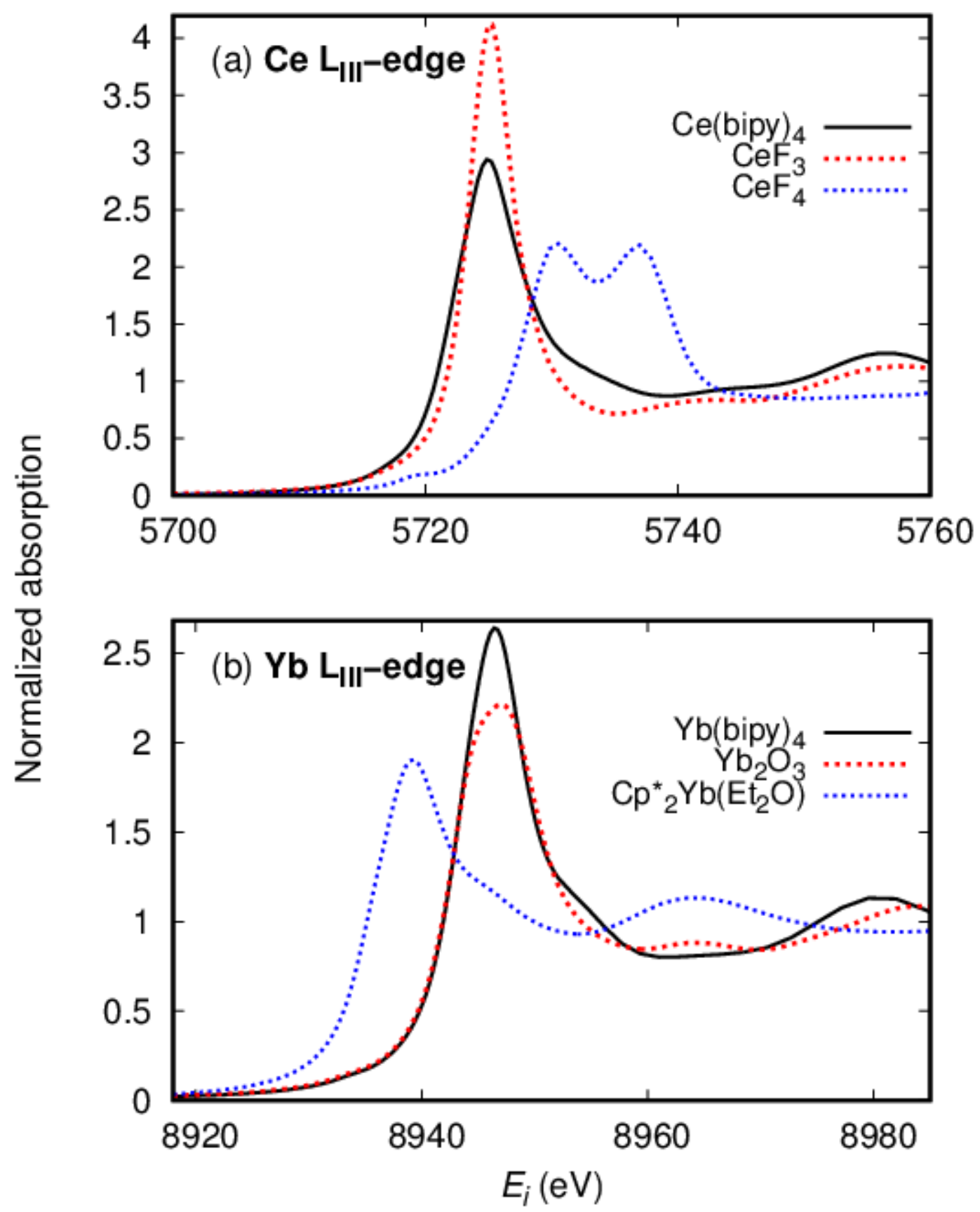

Figure 10. $\mathrm{Ln} \mathrm{L}_{\mathrm{III}}$-edge $\mathrm{XANES}$ of (a) $\mathrm{Ce}\left(\kappa^{2} \text {-bipy) }\right)_{4}$ and (b) $\mathrm{Yb}\left(\kappa^{2} \text {-bipy }\right)_{4}$, with $\mathrm{CeF}_{3}$ and $\mathrm{CeF}_{4}$ as $\mathrm{Ce}(\mathrm{III})$ and $\mathrm{Ce}(\mathrm{IV})$ and $\mathrm{Cp}_{2}{ }_{2} \mathrm{Yb}\left(\mathrm{Et}_{2} \mathrm{O}\right)$ and $\mathrm{Yb}_{2} \mathrm{O}_{3}$ as $\mathrm{Yb}(\mathrm{II})$ and $\mathrm{Yb}(\mathrm{III})$ displayed for reference, respectively. The data demonstrate a $\mathrm{Ln}^{\mathrm{III}}$ valence state for these bipy 4 compounds.

Both $\mathrm{La}\left(\kappa^{2} \text {-bipy }\right)_{4}$ and $\mathrm{Ce}\left(\kappa^{2} \text {-bipy }\right)_{4}$ were studied by EPR spectroscopy (Figure S5-S9). The La complex shows a narrow and well-defined resonance at 2.0012 (room temperature) in 
agreement with the presence of a bipy radical anion. No hyperfine or superhyperfine structure could be detected, either at room $(300 \mathrm{~K})$ of low $\mathrm{T}(2 \mathrm{~K})$ due to the presence of the metal center. For the $\mathrm{Ce}\left(\kappa^{2} \text {-bipy }\right)_{4}$ complex, a strong peak at $g=2.003$ was observed at room temperature but this peak is much narrower and weaker than the corresponding peak observed in the EPR spectrum of $\mathrm{La}\left(\kappa^{2}-\text { bipy }\right)_{4}$. Additionally, at low temperature, there is a very small peak at 3.70 which could correspond to $g_{/ /}$for the $m_{j}= \pm 5 / 2$ state. These observations agree with a $\mathrm{Ce}(\mathrm{III}), \mathrm{f}^{1}$ configuration and a least one bipy radical anion.

\section{Computational studies.}

In the following paragraph, the notation for the electronic description is given as follows: the wave function of the four $\pi^{*}$ molecular orbitals for the four bipyridine ligands is written as $\left(\pi_{1}^{*}\right)^{\mathrm{a}},\left(\pi_{2}^{*}\right)^{\mathrm{b}},\left(\pi_{3}^{*}\right)^{\mathrm{c}}$, and $\left(\pi_{4}^{*}\right)^{\mathrm{d}}$, where the a to $\mathrm{d}$ superscripts are $0, \alpha$ or $\beta$, or $\alpha / \beta$ and used to indicate that the orbital is vacant, half-vacant, or fully occupied, respectively. The symbol $\mathrm{f}^{\mathrm{x}}$ (colored in red) indicates the metal electron configuration and $\mathrm{x}$ superscript is either $0, \alpha$ or $\beta$, or $\alpha / \beta$ and take the values of zero, one or a pair of electrons, respectively. For a trivalent metal center, the sum of the superscript $(a+b+c+d)$ equals three. The $f^{x}$ nomenclature for the metal is used to specify the total electron population in the hybrid orbitals that may be distributed in the $6 \mathrm{~s}, 5 \mathrm{~d}$, and $4 \mathrm{f}$ orbitals. For example, for $\mathrm{Ce}$, the nomenclature is $\mathrm{f}^{1}$ but the metal orbitals used are mixed $6 \mathrm{~s}, 5 \mathrm{~d}$, and $4 \mathrm{f}$ orbitals whose total population is 1 of either $\alpha$ or $\beta$ spins.

The geometry of the monomeric eight coordinate molecules is determined from DFT calculations in which the metal is trivalent and the three electrons are distributed over four bipy $\pi^{*}$ ligands. The Cartesian coordinates are available in SI. The geometry optimizations were carried out using the hybrid B3PW91 functional. For the $\mathrm{H}, \mathrm{C}$ and $\mathrm{N}$ atoms the 6$31 \mathrm{G}(\mathrm{d}, \mathrm{p})$ double $\zeta$ basis set is used and the lanthanide atoms were treated with the Stuttgart- 
Köln relativistic effective core potentials (RECP). The electronic states of the $\mathrm{M}\left(\kappa^{2}-\mathrm{bipy}\right)_{4}$ complexes are analyzed using the Complete Active Space Self-Consistent Field (CASSCF) approach. At this point in the analysis, an adequate selection of the complete active space (CAS) is crucial as a first step in the implementation of this multireference method. In order to determinate the optimal sets of molecular orbitals (MOs) for each $\mathrm{M}\left(\kappa^{2}-\text { bipy }\right)_{4}$ complex, systematic Restricted Open-shell Hartree-Fock (ROHF) calculations were carried out for the different spin values, $S=1 / 2,1$ and $3 / 2$ in the La case and $S=0,1$ and 2 for the Ce complex. Once the SCF MOs were obtained and carefully analyzed, the computational procedure developed in previous studies of multiconfigurational ground-state calculations has been applied. Firstly, calculations were carried out including all the seven $4 \mathrm{f}$ orbitals and the $4 \pi^{*}$ orbitals. Analyzing the results indicated that only one 4 f orbital was important to describe the different electronic states as well as the four $\pi^{*}$. Therefore, the active space was reduced to three electrons and four orbitals (HOMO-2, HOMO-1, HOMO and LUMO) were used as an input to perform the extensive CASSCF calculations. For the $\mathrm{La}\left(\kappa^{2}-b i p y\right)_{4}$ complex these four orbitals are part of a set of MOs of the spin quartet state $(S=3 / 2)$. Likewise, each one of them corresponds to one $\pi^{*}$ MO localized in each bipyridine ligand. For the $\mathrm{Ce}\left(\kappa^{2}-\mathrm{bipy}\right)_{4}$ complex, the active space was defined by four electron and five active orbitals (one sdf hybrid metallic orbital and four bipy $\pi^{*}$ molecular orbitals) coming from the triplet state $(\mathrm{S}=1)$. It is important to note that for all complexes, CASSCF calculations have been carried out by computing the first and the second roots for each spin value mentioned previously.

In Figure 10-13, the results obtained are summarized at the CASSCF level for the ground state and the two lowest excited states of the $\mathrm{M}\left(\kappa^{2} \text {-bipy }\right)_{4}$ complexes, $\mathrm{M}=\mathrm{La}, \mathrm{Ce}, \mathrm{Yb}$, and Lu. 


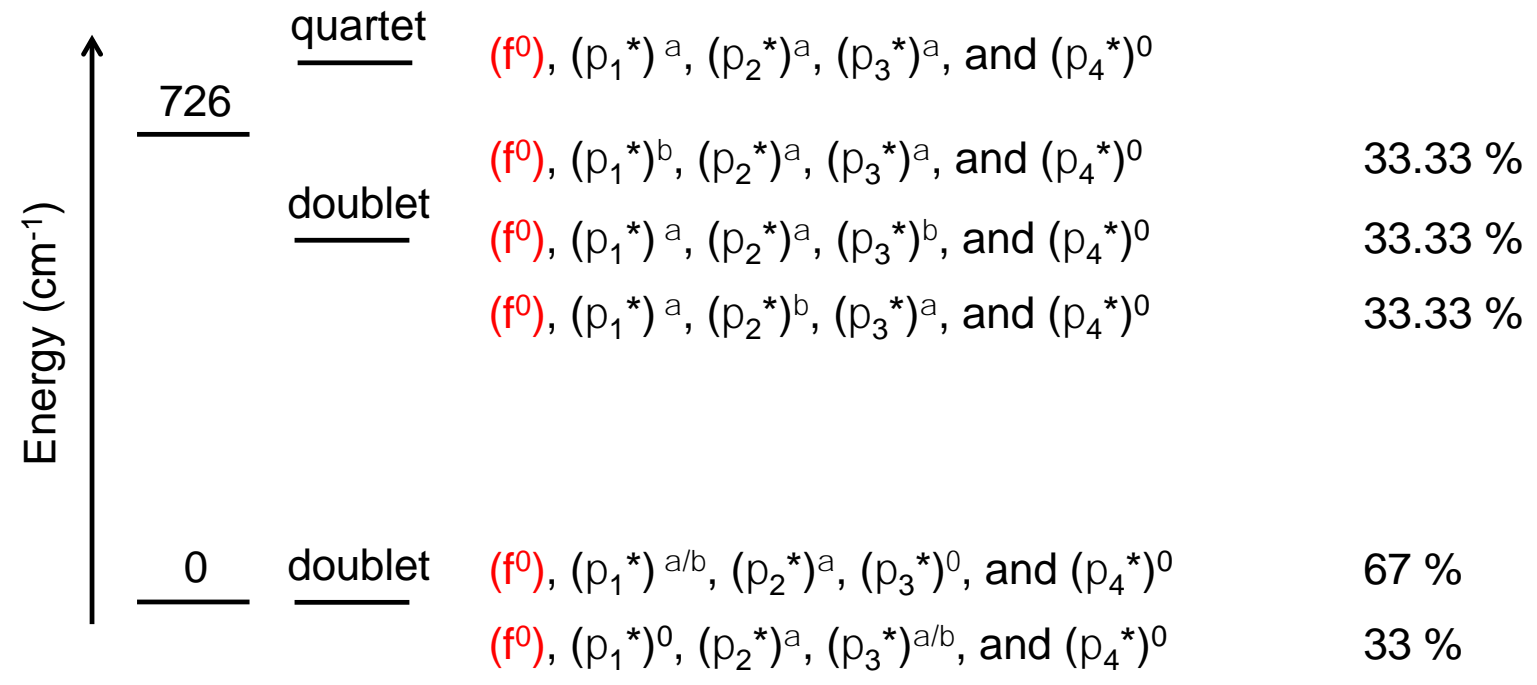

Figure 11. Energy levels and configuration of La $\left(\right.$ III, $\left.f^{\mathrm{x}}\right)\left(\pi_{1}^{*}\right)^{\mathrm{a}},\left(\pi_{2}^{*}\right)^{\mathrm{b}},\left(\pi_{3}^{*}\right)^{\mathrm{c}}$ and $\left(\pi_{4}^{*}\right)^{\mathrm{d}}$.

The calculated ground electronic state for the monomeric lanthanum molecule, Figure 11, is a multiconfigurational spin doublet in which one bipy $\pi^{*}$ molecular orbital contains a pair of electrons with opposite spin and another molecular orbital contains a single electron. The two configurations do not equally contribute (67\% and 33\%, respectively). The energy of the second doublet and quartet states are $726 \mathrm{~cm}^{-1}$ above the ground state. The ground doublet state is multiconfigurational and each of the configurations contributes equally. The quartet state is a single configuration. The second doublet state contains three configurations in which the three bipy $\pi^{*}$ molecular orbital are populated by a single electron have a net spin of $S=1 / 2$ and that of the quartet is $S=3 / 2$.

In the following, it is assumed that the calculated energies of the monomeric units are a guide for how the monomeric units are assembled into the polymeric networks. The single electron in the doublet states can antiferromagnetically couple in the growing polymer resulting in decreasing in the value of $\mu_{\text {eff }}$ with decreasing temperature, Figure 7 . The value of $\mu_{\text {eff }}$ at 300 $\mathrm{K}$ is approximately $30 \%$ higher than expected for a spin doublet in $\mathrm{La}\left(\kappa^{2}-\mathrm{bipy}\right)_{4}$. This may be rationalized by thermal population of the spin quartet state in the individual monomers. 
The A-distances, in Table 4 factor into two short and two longer distances in the crystal structure, Figure 4, consistent with two of the four molecular orbitals containing a pair of electrons with opposite spin and a single electron, respectively, in the doublet ground state and excited state and population of the isoenergetic quartet state resulting from the Boltzmann factor.

For the cerium complex $\mathrm{Ce}\left(\kappa^{2} \text {-bipy }\right)_{4}$, two sets of computations were obtained; one using the calculated DFT structure for cerium and the other from the replacement of cerium in the calculated lanthanum structure. The results for the $\mathrm{Ce}$ in La structure is shown below since the $\mathrm{La}\left(\kappa^{2} \text {-bipy }\right)_{4}$ and $\mathrm{Ce}\left(\kappa^{2} \text {-bipy }\right)_{4}$ are isostructural in the solid-state. The cerium structure has a triplet ground state followed by a singlet and a triplet excited state of several configurations. The calculated electronic structure of the ground state of $\mathrm{Ce}\left(\kappa^{2}-b i p y\right)_{4}$ in the lanthanum structure is a multiconfigurational triplet, Figure 12 . The configurations of the $\pi^{*}$ molecular orbitals of bipy are similar to those in the ground state doublet of $\mathrm{La}\left(\kappa^{2}-\mathrm{bipy}\right)_{4}$, the difference being that the triplet results from $\mathrm{Ce}^{\mathrm{III}}, \mathrm{f}^{1}$. A singlet state, also multiconfigurational and based on $\mathrm{Ce}^{\mathrm{III}}, \mathrm{f}^{1}$ lies $40 \mathrm{~cm}^{-1}$ higher in energy and another spin triplet that is also multiconfigurational lies $726 \mathrm{~cm}^{-1}$ higher in energy. 


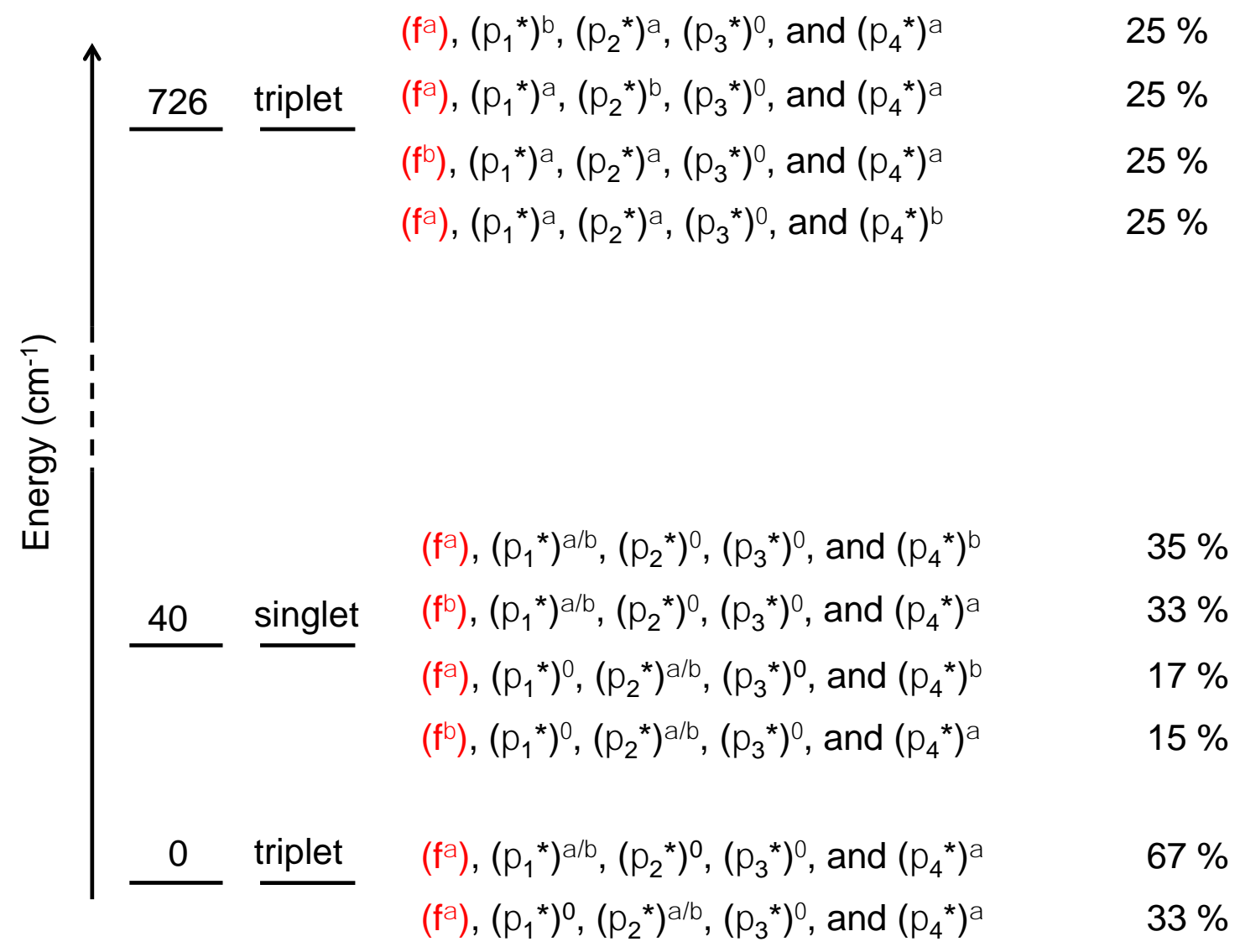

Figure 12. Energy levels and configuration of Ce (III, $\left.(\mathrm{f})^{\mathrm{x},}\right)\left(\pi_{1}^{*}\right)^{\mathrm{a}},\left(\pi_{2}\right)^{\mathrm{b}},\left(\pi_{3}^{*}\right)^{\mathrm{c}}$ and $\left(\pi_{4}\right)^{\mathrm{d}}$

The close similarity between the electronic ground states of $\mathrm{La}\left(\kappa^{2}-\text { bipy }\right)_{4}$ and $\mathrm{Ce}\left(\kappa^{2}-\text { bipy }\right)_{4}$ accounts for their similar bond lengths in Table 4 . The value of $\mu_{\text {eff }}$ at $300 \mathrm{~K}$ is approximately $20 \%$ lower than expected for $\mathrm{Ce}^{\mathrm{III}}$, in which the metal and ligand spins are not interacting; thermal population of the spin singlet may be postulated to account for the lowered value; the triplet energy lying below the singlet is inverse of Van Vleck behavior. In the first three configurations, the $4 \mathrm{f}^{1}$ configuration dominates, consistent with the $\mathrm{L}_{\mathrm{III}}$-XANES spectra.

The computed ground electronic state for $\mathrm{Yb}\left(\kappa^{2} \text {-bipy }\right)_{4}$, Figure 13, is a multiconfigurational triplet, in which the total spin of the ligand orbitals of $S=1 / 2$ is aligned with the metal orbitals, also of $S=1 / 2$. The configurations of the three ligand-based orbitals do not contribute equally to the total energy of the triplet state. The next two excited states are 
multiconfigurational singlets that lie only $6 \mathrm{~cm}^{-1}$ and $24 \mathrm{~cm}^{-1}$ above the triplet again demonstrating inverse Van Vleck behavior. Note that the configurations shown in Figure 13 do not include phase effects for the $\mathrm{f}^{14}$ states. For example, the first excited state of $\mathrm{Yb}$ is a singlet multireference with $54 \% \mathrm{f}^{13}$ and $46 \% \mathrm{f}^{14}$. However, in the latter state, the two $\mathrm{f}^{14}$ determinants have opposite signs in the wavefunction so that their contributions to the final value nearly vanish. As in our previous work, ${ }^{17,18}$ after adding the $\mathrm{f}^{12}$ and $\mathrm{f}^{\mathbf{1 3}}$ configuration fractions, these calculations indicate an $\mathrm{Yb}$ valence of +2.98 and +2.99 for the two excited states, consistent with the XANES shown in Figure 10. The composition of the ten configurations in the singlets is multiconfigurational in metal and ligand based orbitals. The higher lying multiconfigurational singlet and triplet states are only $161 \mathrm{~cm}^{-1}$ above the ground state. 


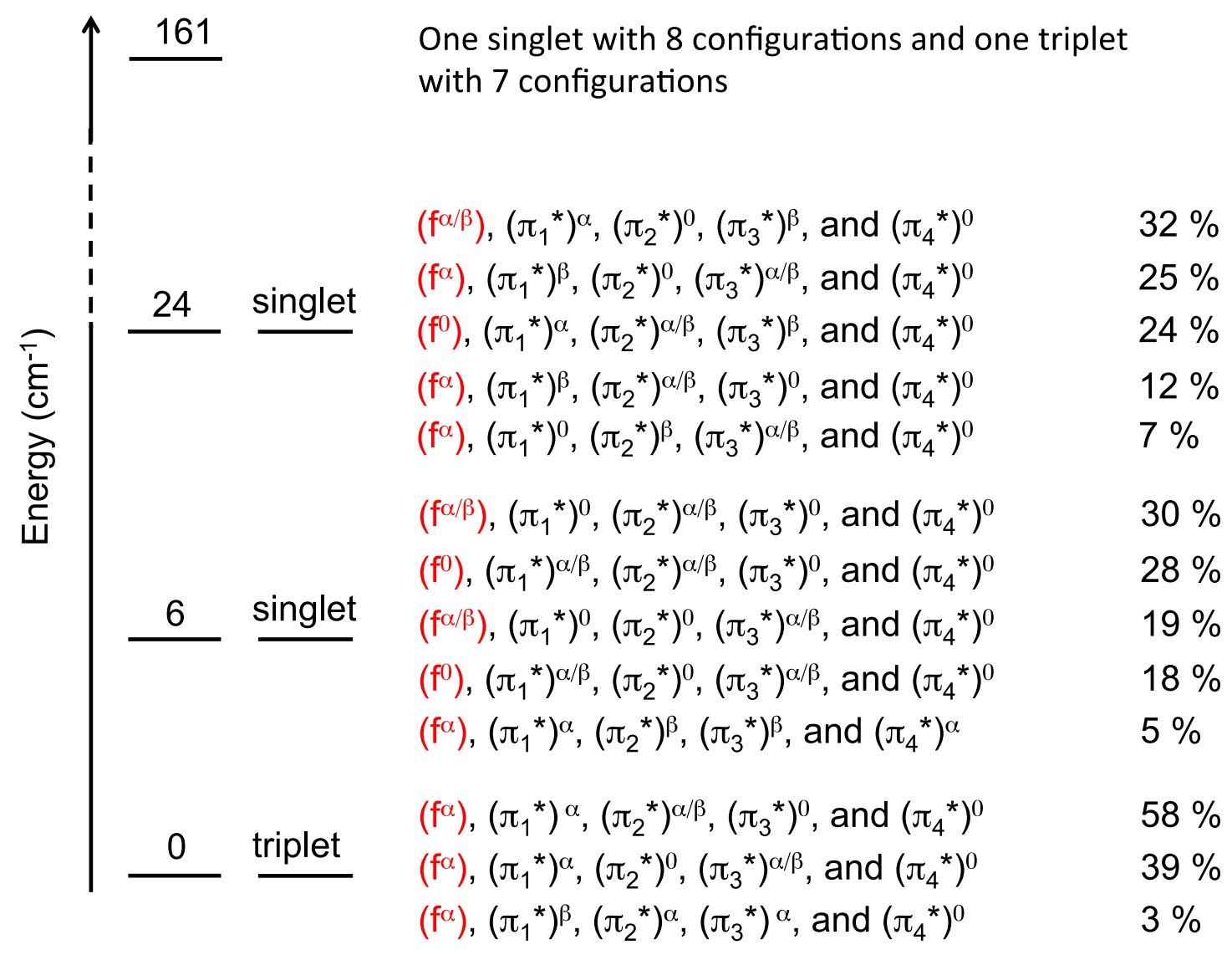

Figure 13. Energy levels and configuration of $\mathrm{Yb}\left(\mathrm{III},(\mathrm{f})^{\mathrm{x}}\right),\left(\pi_{1}^{*}\right)^{\mathrm{a}},\left(\pi_{2}\right)^{\mathrm{b}},\left(\pi_{3}^{*}\right)^{\mathrm{c}}$ and $\left(\pi_{4}^{*}\right)^{\mathrm{d}}$ All states show a nearly trivalent $\mathrm{Yb}$, see main text.

The computed multiconfigurational ground state of $\mathrm{Lu}\left(\kappa^{2}-b i p y\right)_{4}$ is a spin doublet composed of the two configurations with populations of 45:55 and the two higher energy multiconfigurational doublets are only $24 \mathrm{~cm}^{-1}$ and $32 \mathrm{~cm}^{-1}$ above the ground state, Figure 14 . There is a complementarity between the spin doublet ground states of $\mathrm{La} / \mathrm{Lu}$ and the spin triplet ground states of $\mathrm{Ce} / \mathrm{Yb}$ in which the f-configurations are $4 \mathrm{f}^{0}$ and $4 \mathrm{f}^{1} / 4 \mathrm{f}^{13}$, respectively, but the energy difference between the ground and first excited states are much smaller in the $\mathrm{Yb} / \mathrm{Lu}$ pairs than the $\mathrm{La} / \mathrm{Ce}$ pair. 


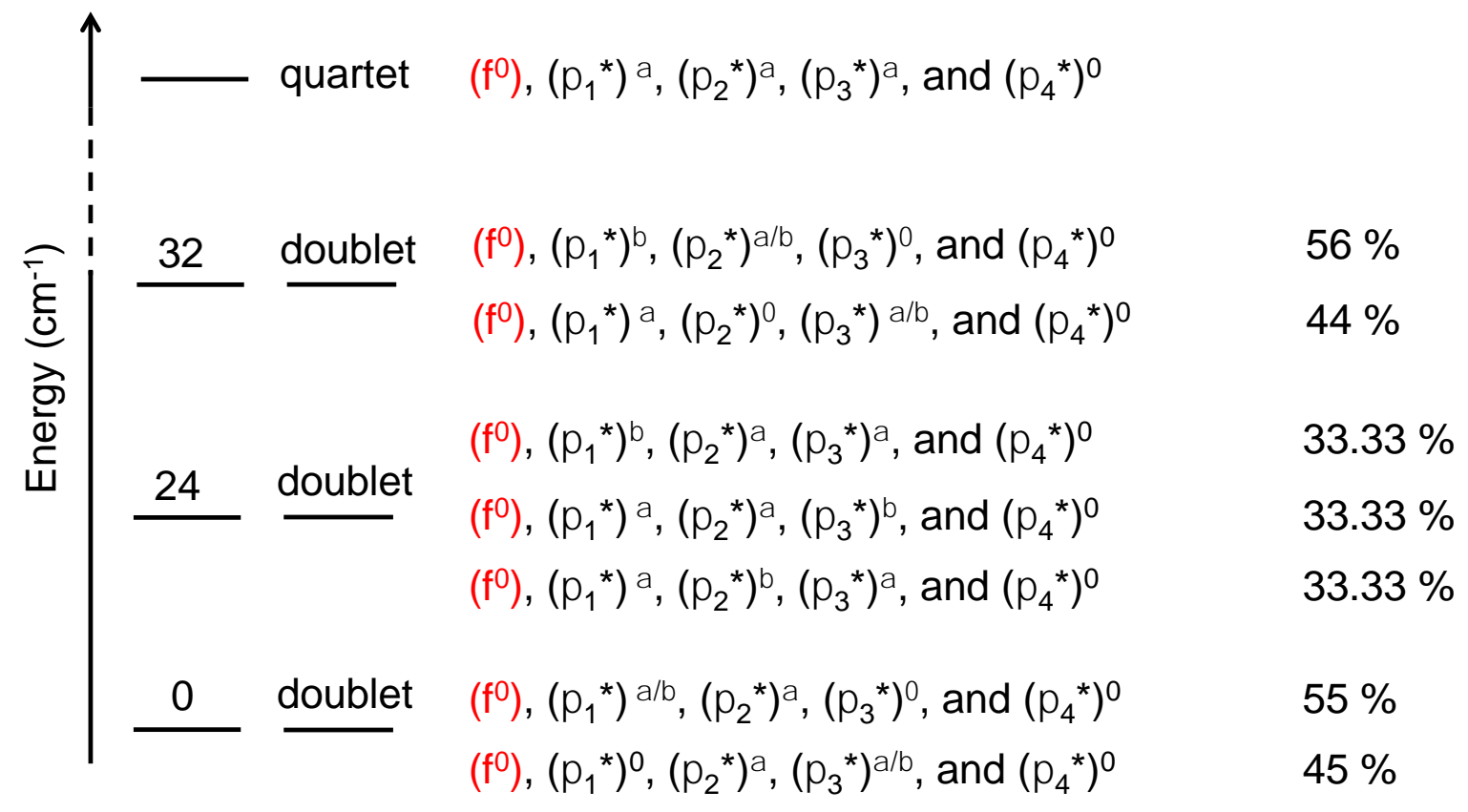

Figure 14. Energy levels and configuration of Lu (III, $\left.(\mathrm{f})^{\mathrm{x}}\right),\left(\pi_{1}^{*}\right)^{\mathrm{a}},\left(\pi_{2}^{*}\right)^{\mathrm{b}},\left(\pi_{3}^{*}\right)^{\mathrm{c}}$ and $\left(\pi_{4}^{*}\right)^{\mathrm{d}}$

\section{DISCUSSION.}

It is informative to compare the solid-state crystal structures of the neutral bipyridine compounds of $\mathrm{La}\left(4 \mathrm{f}^{0}\right)$ and $\mathrm{Ce}\left(4 \mathrm{f}^{1}\right)$ with those of $\mathrm{Lu}\left(4 \mathrm{f}^{14}\right)$ and $\mathrm{Yb}\left(4 \mathrm{f}^{13}\right)$ since $\mathrm{La}(\mathrm{III})$ and $\mathrm{Lu}(\mathrm{III})$ are closed-shell and $\mathrm{Ce}(\mathrm{III})$ and $\mathrm{Yb}(\mathrm{III})$ have an electron and a hole in their f-shells, respectively. In the crystal, the $\mathrm{La} / \mathrm{Ce}$ structures are isomorphous and isostrutural in space group $\mathrm{C} 2 / \mathrm{c}$ while those of $\mathrm{Yb} / \mathrm{Lu}$ crystallize in space group $P 2_{1} / \mathrm{c}$ and $P c a n$, respectively. ${ }^{5}$

The geometry of $\left[\mathrm{M}\left(\kappa^{2}-\text { bipy }\right)_{4}\right], \mathrm{M}=\mathrm{La}, \mathrm{Ce}$, are close to that of a square prism as indicated by the shape parameters in Table 7 , while those of $\mathrm{Yb} / \mathrm{Lu}$ have a slightly distorted $\mathrm{D}_{2 \mathrm{~d}^{-}}$ dodecahedral geometry. The different geometries can be rationalized by the increased intramolecular repulsions between the ortho $\mathrm{C} \alpha-\mathrm{H} . . \mathrm{H}-\mathrm{C} \alpha$ groups as the metal radii contract across the series; the cube to dodecahedral distortion minimizing this repulsion. 
Table 7. Shape parameters for $\left[\mathrm{M}\left(\kappa^{2}-\text { bipy }\right)_{4}\right]$ and $\left[\mathrm{Li}(\text { thf })_{4}\right]\left[\mathrm{M}\left(\kappa^{2}-\text { bipy }\right)_{4}\right]$ symbolized by $\mathrm{M} /$ $\mathrm{MLi} / \mathrm{Na}$.

\begin{tabular}{|c|c|c|c|c|c|c|c|c|c|}
\hline $\mathrm{M} / \mathrm{M} \mathrm{Li} / \mathrm{Na}$ & $\partial_{1}\left(^{\circ}\right)$ & $\partial_{2}\left(^{\circ}\right)$ & $\partial_{3}\left(^{\circ}\right)$ & $\partial_{4}\left(^{\circ}\right)$ & $\begin{array}{l}\phi_{1} \\
\left(^{\circ}\right)\end{array}$ & $\phi_{2}\left(^{\circ}\right)$ & M-L & $\mathrm{d}$ & ref \\
\hline $\mathrm{D}_{2 \mathrm{~d}}$ Dodecahedron & 29.5 & 29.5 & 29.5 & 29.5 & 0 & 0 & / & I & $\mathrm{a}$ \\
\hline $\begin{array}{l}\mathrm{D}_{4 \mathrm{~d}} \text { Square } \\
\text { Antiprism }\end{array}$ & 0 & 0 & 52.4 & 52.4 & 24.5 & 24.5 & / & / & $\mathrm{a}$ \\
\hline $\mathrm{O}_{\mathrm{h}}$ Cube & 0 & 0 & 0 & 0 & 0 & 0 & I & / & $\mathrm{a}$ \\
\hline $\begin{array}{l}\mathrm{C}_{2 \mathrm{v}} \text { Bicapped } \\
\text { Trigonal Prism }\end{array}$ & 0 & 21.8 & 48.2 & 48.2 & 14.1 & 14.1 & / & / & $\mathrm{a}$ \\
\hline $\mathrm{Ce}$ & 1.21 & 1.21 & 6.63 & 8.04 & 2.05 & 2.86 & $2.63(3)$ & 1.02 & $\mathrm{~b}$ \\
\hline $\mathrm{La}$ & 0.91 & 0.91 & 6.40 & 7.26 & 1.83 & 2.71 & $2.65(3)$ & 1.01 & $\mathrm{~b}$ \\
\hline $\mathrm{Tb}$ & 10.84 & 14.87 & 40.79 & 41.06 & 1.86 & 25.38 & $2.50(2)$ & 1.08 & $\mathrm{~b}$ \\
\hline $\mathrm{Sm}$ & 1.39 & 1.39 & 7.45 & 8.84 & 1.83 & 2.71 & $2.58(3)$ & 1.03 & $\mathrm{c}$ \\
\hline $\mathrm{Eu}$ & 0.46 & 0.46 & 6.49 & 7.81 & 2.24 & 2.44 & $2.73(5)$ & 0.99 & $\mathrm{c}$ \\
\hline $\mathrm{Yb}$ & 21.14 & 23.16 & 29.06 & 30.16 & 6.44 & 13.76 & $2.45(5)$ & 1.09 & $\mathrm{c}$ \\
\hline $\mathrm{Lu}$ & 25.84 & 27.54 & 30.58 & 32.06 & 7.18 & 11.72 & $2.43(7)$ & 1.10 & $\mathrm{c}$ \\
\hline $\mathrm{Lu} \mathrm{Li}$ & 18.69 & 18.69 & 37.17 & 37.17 & 0.13 & 17.98 & $2.44(2)$ & 1.10 & $\mathrm{c}$ \\
\hline $\mathrm{U}$ & 0.35 & 0.35 & 0.87 & 1.36 & 0.84 & 1.26 & $\begin{array}{c}2.491(8 \\
)\end{array}$ & 1.06 & $\mathrm{~d}$ \\
\hline $\mathrm{UNa}$ & 1.31 & 1.92 & 3.74 & 3.8 & 1.78 & 2.38 & $2.50(4)$ & 1.05 & $d$ \\
\hline
\end{tabular}

$\mathrm{d}$ is the normalized bite angle $(\mathrm{d}=\mathrm{d}(\mathrm{NN}) / \mathrm{d}(\mathrm{MN}))$; a ref $19, \mathrm{~b}$ is his work, $\mathrm{c}$ is ref 5 and $\mathrm{d}$ ref 20

The distribution of the three electrons in the LUMO of the coordinated bipyridine ligands is readily deduced from the $\mathrm{M}-\mathrm{N}$ and A-distances (Table 2). The isostructural $\mathrm{La} / \mathrm{Ce}$ pair have two short and two longer A-distances. The two shorter A-distances are associated with the bidentate bipy rings labeled 1, colored in red, while the longer set are associated with rings labeled 2, colored in green. Each pair of equivalent rings that are labeled 1 and 2 , 
respectively, are related by a $\mathrm{C}_{2}$-axis, Figure 3 . The A-distances in ring 1 are close to the value of the equivalent distances in an isolated bipy radical anion while those in ring 2 are midway between the equivalent distance in a bipyridine radical and free bipyridine. The M-N distance associated with ring 1 are shorter than those associated with ring 2 . The bond distance pattern suggests that the two bipyridine ligands labeled 1 are formulated as bipy ${ }^{(-1)}$ and those labeled 2 are bipy $^{(-1 / 2)}$; this valence bond representation is labeled as a 2:2 pattern. The geometry and pattern of M-N and A-distances change in the structures of the $\mathrm{Lu} / \mathrm{Yb}$ pairs (Table 4) as three bipy ligands have A-distances that are close to the values associated with ring 1 while the A-distance in the remaining bipy ligand is close to that in the free bipyridine and is labeled ring 2. The M-N distances follow the ring 1/ring 2 pattern resulting in a (bipy ${ }^{(-}$ $\left.{ }^{1)}\right)_{3}(\text { bipy })^{(0)}$ formulation, that is, three radical anion and one neutral bipy (3:0 pattern).

The only other crystal structures for the neutral complexes in the literature are those of the $\mathrm{Sm} / \mathrm{Eu}$ atom pairs. ${ }^{5}$ These pairs are also isomorphous and isostructural with the $\mathrm{La} / \mathrm{Ce}$ pair with nearly square prismatic geometries (Table 4). The Eu/Sm bond length patterns are similar to those found in the isomorphous and isostructural $\mathrm{La} / \mathrm{Ce}$ structures. For the $\mathrm{Sm}$ structure, the A-distance in ring 1 and ring 2 follow the pattern in the La/Ce pair and therefore are classified as a 2:2 pattern. However, the bond distances pattern is different in the Eu structure; although the A-distance in ring 1 results in their classification as $\left(\text { bipy }^{(-1)}\right)_{2}$, those in ring 2 are similar that in free bipy and classified as $\left(\text { bipy }{ }^{(0)}\right)_{2}$ and therefore display 2:0 pattern.

Crystal structures of the two anionic compounds are available, $\left[\mathrm{Li}(\mathrm{thf})_{4}\right]\left[\mathrm{M}\left(\kappa^{2}-\mathrm{bipy}\right)_{4}\right]$ for $\mathrm{M}$ $=\mathrm{Tb}($ Figure 5$)$ and Lu. ${ }^{5}$ Both crystallize in the monoclinic crystal system in space group $\mathrm{C}_{2 / \mathrm{c}}$ and $\mathrm{P}_{21 / \mathrm{c}}$, respectively. The geometry of the anions resembles that of a $\mathrm{D}_{2 \mathrm{~d}}$ dodecahedron. The A-distances in the four bidentate bipy ligands are equal and their value is close to that of the 
equivalent distance in a bipy radical anion. The eight $\mathrm{M}-\mathrm{N}$ distances are also equal to within $3 \sigma$, resulting in the bipy ligands being classified as a 4:0 pattern.

The systematics associated with the A- and M-N distances of the bidentate bipyridine ligands in the crystal structures of the neutral compounds described in this article and those in the literature, ${ }^{5}$ that is, $\mathrm{La}, \mathrm{Ce}, \mathrm{Sm}, \mathrm{Yb}$, and Lu show that the LUMO of each of the four bipy ligands contain three electrons. The $\mathrm{A}, \mathrm{B}, \mathrm{C}$, and $\mathrm{D}$ distances and the infrared absorptions show features associated with bipy radical anions. The distribution of radical anionic character in the four ligands however is different, and is associated with the different geometry of the eight coordinate compounds. The bipy ligands in $\mathrm{La}, \mathrm{Ce}$, and $\mathrm{Sm}$ have a 2:2 distribution but those in $\mathrm{Yb}$ and $\mathrm{Lu}$ have a 3:0 distribution. The geometries for the former are cubes while those for the latter are dodecahedral. The bipy ligands in $\mathrm{Eu}\left(\kappa^{2}-\mathrm{bipy}\right)_{4}$, which is isostructural with $\mathrm{Sm}$, contain two bipy radical anions and therefore a 2:0 distribution. The four bipy ligands in the two anionic compounds are classified as bipy radical anions and the distribution is classified as 4:0 and the geometries are irregular dodecahedral.

Although, this empirical classification is helpful to classify the general pattern developed from the A-distances with the dependence on the metal and their geometries, the computational results give deeper meaning to how the ground and excited states energies change that blurs the simple valence bond classification. The computations of the gas phase monomeric building blocks in the polymeric solid for $\mathrm{M}\left(\kappa^{\square} \text {-bipy }\right)_{4}, \mathrm{M}=\mathrm{La}$ and $\mathrm{Ce}$, show that the ground electronic states are spin doublets and triplets, respectively. The configuration of the metallic orbitals in lanthanum is $\mathrm{f}^{0}$ and cerium is $\mathrm{f}^{1}$ and the configuration of the latter is multiconfigurational and composed of $6 \mathrm{~s}, 5 \mathrm{~d}$, and $4 \mathrm{f}$ parentage. The Ce $\mathrm{L}_{\mathrm{III}}$-edge XANES spectrum is consistent with trivalent cerium in the solid-state. The spin doublet and triplet states result from the three electrons distributed in four bipy $\pi^{*}$ molecular orbitals. In both 
molecules, the ground states are multiconfigurational in which a $\pi^{*}$ orbital is occupied by a pair of electrons $\left(\pi^{*}\right)^{\alpha / \beta}$ and the remaining electron occupies a $(\pi)^{\alpha}$ orbital.

In the crystal structure of these two isomorphous and isostructural molecules, the $\mathrm{C}_{2}$ axis interconverts two pairs of bipyridine ligands that are labeled ring 1 and ring 2 . The pair of electrons in $\left(\pi^{*}\right)^{\alpha / \beta}$ have a probability of being located in the two symmetry related orbitals with the shorter A-distance (ring 1) in the multiconfigurational ground states and the single electron has a probability of being found in the symmetry orbitals with the longer A-distance (ring 2), qualitatively accounting for these differences. The CASSCF calculations were not attempted for $\mathrm{Sm}\left(\kappa^{\square} \text {-bipy }\right)_{4}$ due to the large number of active electrons and the resulting larger active space. The crystal structures of the $\mathrm{La}, \mathrm{Ce}$, and $\mathrm{Sm}$ compounds are isostructural and isomorphous and have nearly identical shape parameters (Table 7). The equivalent bond distances also display the same pattern (Table 4) implying they have similar electronic structures.

The CASSCF calculational results for the complementary atom pairs $\mathrm{Lu}(\mathrm{La})$ and $\mathrm{Yb}(\mathrm{Ce})$ are given in Figures 10-13. The calculated ground state of $\mathrm{Lu}\left(\kappa^{\square}-\text { bipy }\right)_{4}$ is a spin doublet, as is $\mathrm{La}\left(\kappa^{\square} \text {-bipy }\right)_{4}$ and the configurations of the $\pi^{*}$ orbitals have the same form as those for $\mathrm{La}\left(\kappa^{\square} \text {-bipy }\right)_{4}$. However, the energy between the ground doublet state and the two higher energy doublets are only $24 \mathrm{~cm}^{-1}$ and $32 \mathrm{~cm}^{-1}$ above the ground state, substantially smaller than in the lanthanum molecule. The calculated ground and first excited state in $\mathrm{Yb}\left(\kappa^{\square}-\right.$ bipy) ${ }_{4}$, a triplet and singlet, respectively, is separated by only $6 \mathrm{~cm}^{-1}$ and the next singlet by $24 \mathrm{~cm}^{-1}$ as in the lutetium; these energies are much smaller than those in cerium; these energy changes between $\mathrm{La} / \mathrm{Ce}$ and $\mathrm{Yb} / \mathrm{Lu}$ are presumably related to the larger effective charge $\left(\mathrm{Z}_{\text {eff }}\right)$ for the latter pair. The $\mathrm{Yb}$ metallic orbital is also multiconfigurational. The $\mathrm{Yb} \mathrm{L}_{\mathrm{III}}$-edge XANES spectrum indicates that the metal is trivalent. However, the small energy difference 
between ground and excited states complicates the interpretation of the magnetic susceptibility values since the different states will be thermally populated by the Boltzmann factor, for which $\mathrm{kT}=208 \mathrm{~cm}^{-1}$ at $300 \mathrm{~K}$. Although the M-N and A-distances follow the patterns observed in $\mathrm{La} / \mathrm{Ce}$, the $\mathrm{Lu} / \mathrm{Yb}$ compounds are not isomorphous with the former pair and have different shape parameters which adds an additional level of complexity. The shape parameters show that the geometries undergo a distortion from square pyramidal ( $\mathrm{La}, \mathrm{Ce}$, $\mathrm{Sm})$ to dodecahedral $(\mathrm{Yb}, \mathrm{Lu})$, presumably due to relief of intramolecular steric repulsions as the radii contract. In summary, the ground state electronic structure of $M\left(\kappa^{\square}-b i p y\right)_{4}(M=L a$, $\mathrm{Ce}, \mathrm{Sm}, \mathrm{Yb}, \mathrm{Lu})$ follow similar pattern even though their geometries change.

The molecule that deviates from the above pattern is $\operatorname{Eu}\left(\kappa^{\square} \text {-bipy }\right)_{4}$. Although this compounds is isomorphous, isostructural and has shape parameters close to those of $\mathrm{La}, \mathrm{Ce}$, and $\mathrm{Sm}$, the bond lengths do not follow the pattern set forth in Table 4. The Eu-N distances in ring 1 and 2 are $0.14 \AA$ and $0.18 \AA$ longer than the equivalent distances in $\operatorname{Sm}\left(\kappa^{\square} \text {-bipy }\right)_{4}$. If both metals were trivalent these distances would be similar since their trivalent metal radii in identical coordination numbers are $1.09 \AA(\mathrm{Sm})$ and $1.10 \AA(\mathrm{Eu}){ }^{21}$ Since the divalent radius of europium is $0.21 \AA$ larger than that of trivalent europium the longer Eu-N distances strongly supports the divalent classification. This is supported by the A-distances in rings 1 and 2 of 1.417(7) $\AA$ and 1.484(7) $\AA$, respectively, the former is midway between the equivalent distances of bipy ${ }^{(-2)}$ and bipy ${ }^{(-1)}$ and the latter is identical to that in bipy ${ }^{(0)}$. This deduction is supported further by the magnetic susceptibility of $\mu_{\text {eff }}=8.06 \mu_{\mathrm{B}}\left(\chi \mathrm{T}=8.12 \mathrm{~cm}^{3} \cdot \mathrm{K} \cdot \mathrm{mol}^{-1}\right)$ at $300 \mathrm{~K}$. The value for the free metal ion, ${ }^{8} \mathrm{~S}_{7 / 2}$ is $7.94 \mu_{\mathrm{B}}\left(\left(\chi \mathrm{T}=7.88 \mathrm{~cm}^{3} \cdot \mathrm{K} \cdot \mathrm{mol}^{-1}\right)\right.$, which implies that one of the four bipy $\pi^{*}$ orbitals contains two electrons of opposite $\operatorname{spin},\left(\pi^{*}\right)^{\alpha / \beta}$ as in the isostructural neutral compounds. Comparing the plots of $\mu_{\text {eff }}$ vs $T$ of $E u(\kappa-\text {-bipy })_{4}$, with the $\mathrm{La} / \mathrm{Ce}$ analogues, Figure 7 and 9 shows that the former is essentially independent of 
temperature to $\approx 20 \mathrm{~K}$, after which the slope turns gently downwards. This behavior is consistent with the $\mathrm{C} \alpha \ldots \mathrm{C} \beta$ contact distance of $3.31 \AA$ between two rings with long Adistances; the equivalent distance in $\operatorname{Sm}\left(\kappa^{\square} \text {-bipy }\right)_{4}$ is $3.24 \AA$ between bipy ligands with the short A-distances in the polymeric chain. The longer distance implies a weaker interaction due to the lack of antiferromagnetic coupling between the bipy ${ }^{(0)}$ ligands.

Only two crystal structures of the anionic compounds are known, $\left[\operatorname{Li}(\text { thf })_{4}\right]\left[\mathrm{M}\left(\kappa^{2}-\text { bipy }\right)_{4}\right](\mathrm{M}$ $=\mathrm{Tb}\left(\right.$ Figure 5) and $\mathrm{Lu} ;{ }^{5}$ both crystallize in the monoclinic crystal system but in different space groups, $\mathrm{P} 2{ }_{1} / \mathrm{c}$ and $\mathrm{C}_{2} / \mathrm{c}$, respectively. The geometry of the isolated anions is that of a square antiprism with a dodecahedral distortion. Although the geometry is rather irregular, all eight M-N distances are identical as are the A-distances and the latter are close to those found for the equivalent distance in a radical anion. These distances indicate that each of the four $\pi^{*}$ orbitals contain a single electron. No computations were initiated for the ion-pair $\mathrm{Tb} / \mathrm{Dy}$ pair due to the difficulties associated with separated ion pair molecules and the large number of electrons in the active space.

All of the tetra-bipy lanthanide molecules mentioned in the text and Table 7 are based on the trivalent metal ion, the lone exception is that of the Eu complex, which is divalent. This is not surprising since the difference is traced to the third ionization energies relative to those of the second. Although the first ionization energies (IEs) are known for all of the $4 \mathrm{f}$ series, a recent article reported the experimental values (for those that are known) and calculated quantum mechanically the individual $6 \mathrm{~s}, 5 \mathrm{~d}$, and $4 \mathrm{f}$ ionization energies. ${ }^{22}$ The s-orbital IEs range from $\approx 5.4$ to $6.3 \mathrm{eV}$ and the calculated values are close to the experimental ones. The large differences arise from the $\mathrm{d} / \mathrm{f}$-orbitals $\mathrm{IEs}$, which range from $\approx 6.7$ to $11.7 \mathrm{eV}$. The informative comparison is between the $\mathrm{Sm} / \mathrm{Eu}$ pair, in which the f-orbitals IE for $\mathrm{Sm}$ is 9.25 $\mathrm{eV}$ (calcd.) while that for $\mathrm{Eu}$ is $10.5 \mathrm{eV}$ (calcd.). The value for europium is the largest value known in the $4 \mathrm{f}$-block metal series and rationalizes why the europium molecule is the odd 
one in the series. The comparison with $\mathrm{Sm}$ and $\mathrm{Yb}$ is also informative since the f-orbital IE of $\mathrm{Yb}$ is $10.75 \mathrm{eV}$ (calcd.), higher than that for $\mathrm{Eu}$, but the experimental value of $8.95 \mathrm{eV}$ is slightly less than that calculated for Sm. The experimental value is in line with the deduction that ytterbium is trivalent in $\mathrm{Yb}\left(\kappa^{2} \text {-bipy }\right)_{4}$. The other revealing comparison is that the $5 \mathrm{~d}$ orbital IE in cerium is only $6.75 \mathrm{eV}$ (calcd. and exp.) and the f-orbital IE is $11.13 \mathrm{eV}$ (calcd.) and $11.81 \mathrm{eV}(\exp )$; the difference agrees with the conclusion that cerium is trivalent in $\mathrm{Ce}\left(\kappa^{2} \text {-bipy }\right)_{4}$. The orbital IEs provide a qualitative rationalization for why the two spins in the 6s-orbitals are transferred to a pair of symmetry equivalent bipyridine ligand orbitals with a net spin of zero.

\section{CONCLUSIONS.}

Syntheses of $\mathrm{M}\left(\kappa^{2}-\text { bipy }\right)_{4}(\mathrm{M}=\mathrm{La}$ and Ce $)$ and $\left[\operatorname{Li}(\operatorname{thf})_{4}\right]\left[\mathrm{M}\left(\kappa^{2}-\text { bipy }\right)_{4}\right](\mathrm{M}=\mathrm{Dy}, \mathrm{Tb})$ are described along with single X-ray crystal structures and shape parameters that define their eight-coordinate geometries for the neutral $\mathrm{La} / \mathrm{Ce}$ pairs and the $\mathrm{Tb}$ anion. The physical properties that are measured include solid-state magnetism, Ce $\mathrm{L}_{\mathrm{III}}$-edge XANES, EPR, and IR spectra along with solution UV-Vis spectra and computational CASSCF results for La, $\mathrm{Ce}, \mathrm{Yb}$, and $\mathrm{Lu}$.

The molecular structures of $\mathrm{M}\left(\kappa^{2}-\text { bipy }\right)_{4}, \mathrm{M}=\mathrm{La}$ and $\mathrm{Ce}$, are polymeric in the solid-state in which two $\kappa^{2}$-bipy ligands, with the longer M-N distances, bridge between the monomeric units in the polymer chain. The geometry of the eight coordinate, isomorphous compounds define a square prism. The structure of the anion in the separated ion pair $\left[\mathrm{Li}(\mathrm{thf})_{4}\right]\left[\mathrm{Tb}\left(\kappa^{2}-\right.\right.$ bipy $)_{4}$ ] is monomeric whose geometry is a square antiprismatic with a dodecahedral distortion in which the eight $\mathrm{Tb}-\mathrm{N}$ distances are equal. The electronic structures of the gas phase monomeric units, $\mathrm{M}=\mathrm{La}$ and $\mathrm{Ce}$, from $\mathrm{CASSCF}$ multireference quantum mechanical calculations show that the ground states are mutliconfigurational spin doublets and triplets, respectively, built from trivalent metals and four bipy $\pi^{*}$ MOs containing three electrons 
such that the net ligand spin is $S=1 / 2$. The calculated ground electronic states for $M\left(\kappa^{2}-\right.$ bipy) $)_{4}, \mathrm{M}=\mathrm{Lu}$ and $\mathrm{Yb}$, whose geometries resemble that of a dodecahedron, have ground state electronic structures that show a complementarity with the $\mathrm{La} / \mathrm{Ce}$ atom pairs even though they have different geometries and electron counts. The computed ground and excited states for the monomeric units that comprise the polymeric chain provide the basis for interpreting the physical properties in the neutral molecules $\mathrm{M}\left(\kappa^{2}-\right.$ bipy $), \mathrm{M}=\mathrm{La}, \mathrm{Ce}, \mathrm{Sm}, \mathrm{Eu}$, $\mathrm{Yb}$ and $\mathrm{Lu}$ and for the anionic ion pair molecules $\left[\mathrm{Li}(\mathrm{thf})_{4}\right]\left[\mathrm{M}\left(\kappa^{2}-\text { bipy }\right)_{4}\right], \mathrm{M}=\mathrm{Tb}, \mathrm{Dy}$, and $\mathrm{Lu}$. The computed electron configuration of the neutral lanthanide $\left[\mathrm{M}^{\mathrm{III}}\left(\kappa^{2}-\text { bipy }\right)_{4}\right](\mathrm{M}=\mathrm{La}, \mathrm{Ce}$, $\mathrm{Yb}$ and $\mathrm{Lu}$ ) are multiconfigurational. This model is extrapolated to the neutral (Sm, Eu) and anionic $(\mathrm{Tb}, \mathrm{Dy})$ lanthanide bipy compounds in order to rationalize their physical properties. A curious feature of this model is that the electronic ground state for $\mathrm{La} / \mathrm{Lu}$ and $\mathrm{Ce} / \mathrm{Yb}$ are doublets and triplets, respectively rather than singlets and doublets found in the vast number of compounds known for these compounds. Accordingly, this study adds another chapter to the iconic binary bipyridine compounds of the s, p, d-block metals. ${ }^{8,10,23-25}$

The model for the neutral molecules developed above shows that a single Lewis structure or the deduction from single reference molecular orbital calculations are misleading for the coordination compound described herein and as previously advocated for $\mathrm{Ce}(\mathrm{acac})_{4}$, $\mathrm{Ce}(\text { trop })_{4}$ and $\mathrm{Ce}(\text { tmtaa })_{2}{ }^{26-27}$ and organometallic compounds such as $\mathrm{Ce}(\mathrm{Cot})_{2},{ }^{28-31}$ $\mathrm{Cp}_{2} * \mathrm{Yb}$ (bipy), ${ }^{18}$ and related heterocyclic imine adducts. ${ }^{32-37}$

The model for the electronic structures of several lanthanide compounds developed from experimental measurements of their physical properties, are illuminated by mutlireference quantum mechanical calculations. The multireference calculations are essential in the lanthanide molecules for an adequate understanding of their physical properties. Single reference DFT calculations are often inappropriate for the electronic structure developed since they can contradict the reported magnetic susceptibility studies. A recent article reports 
some physical properties for the $\mathrm{U}\left(\kappa^{2} \text {-bipy }\right)_{4}$, augmented by a DFT calculation. ${ }^{20}$ The plot of $\chi \mathrm{T}$ vs $\mathrm{T}$ for $\mathrm{U}\left(\kappa^{2} \text {-bipy }\right)_{4}$ gives a $\chi \mathrm{T}$ value of $2.4 \mathrm{~cm}^{3} \cdot \mathrm{K} \cdot \mathrm{mol}^{-1}$ that approaches zero at low temperature, thus the ground state is likely to be a spin singlet and not likely the spin heptet that is advocated from the DFT calculations that indicates the singlet state is $82500 \mathrm{~cm}^{-1}$ higher in energy. Another recent article demonstrates that multireference calculations are essential for determining the electronic structure of a set of d-transition metal bipyridine ligands. ${ }^{38}$ Specifically, the CASSCF method is capable of distinguishing whether bipy acts as a $\pi$-acceptor or an electron acceptor ligand. Since the crystal field splitting of f-electrons is less than that for d-electrons, this article reinforces our use of CASSCF methodologies for the lanthanide bipyridine compounds.

\section{EXPERIMENTAL SECTION.}

General considerations. All reactions and product manipulations were carried out under dry nitrogen using standard Schlenk and glovebox techniques. Dry, oxygen-free solvents were used throughout these experiments. 2,2'-Bipyridine was dried and purified by sublimation prior to use. Melting points were determined in sealed capillaries prepared under nitrogen and are uncorrected. NMR data were obtained at $400 \mathrm{MHz}$ and $294 \mathrm{~K}$ using the Bruker AVB-400 and AVQ-400 NMR spectrometers. ${ }^{1} \mathrm{H}$ chemical shifts are in $\delta \square$ units $\square$ relative to TMS, and coupling constants $(J)$ are given in Hz. Infrared spectra were recorded as Nujol mulls between KBr plates on a Thermo Scientific Nicolet IS10 spectrometer. Samples for UV-VisNIR spectroscopy were obtained in a Schlenk-adapted quartz cuvette and obtained on a Varian Cary 50 scanning spectrometer. Elemental analyses were determined at the Microanalytical Laboratory of the College of Chemistry, University of California, Berkeley. X-ray structural determinations were performed at CHEXRAY, University of California, Berkeley. $\mathrm{Cp}$ ' ${ }_{3} \mathrm{Ce}, \mathrm{Cp}{ }_{2} \mathrm{Mg}$ metal triflates were prepared as previously described for 
$\mathrm{Ce}(\mathrm{OTf})_{3} .{ }^{39}$ The abreviations used are bipy for 2,2'-bipyridine and $\mathrm{Cp}$ ' for 1,3$\left(\mathrm{Me}_{3} \mathrm{Si}\right)_{3} \mathrm{C}_{5} \mathrm{H}_{3}$, and $\mathrm{Cp}$ ' for $\mathrm{C}_{5} \mathrm{H}_{4} \mathrm{Me}$.

The samples were prepared for X-ray absorption experiments as described previously and the same methods were used to protect the air-sensitive compounds from oxygen and water. ${ }^{18} \mathrm{X}$ ray absorption measurements were made at the Stanford Synchrotron Radiation Lightsource on beamline 11-2. The samples were prepared and loaded into a liquid helium-flow cryostat at the beamline as described previously. ${ }^{18}$ Data were collected at temperatures ranging from 30 to $300 \mathrm{~K}$, using a $\mathrm{Si}(220)$ double-crystal monochromator. A linear extrapolation of the pre-edge absorption was subtracted and the data were roughly normalized to unity above the edge. Energy calibration was performed by setting the peak in the first derivative of the absorption from a $\mathrm{CeO}_{2}$ sample to $5724.0 \mathrm{eV} . \mathrm{CeO}_{2}$ and $\mathrm{Yb}_{2} \mathrm{O}_{3}$ were purchased from commercial suppliers and used without further purification.

Magnetism and EPR. Magnetic susceptibility measurements were made for all samples in a

7 T Quantum Design Magnetic Properties Measurement System that utilizes a superconducting quantum interference device (SQUID). Sample containment and other experimental details have been described previously. ${ }^{40}$ Diamagnetic corrections were made using Pascal's constants. EPR spectra (SI) were obtained with a Varian E-12 spectrometer equipped with an EIP-547 microwave frequency counter and a Varian E-500 gaussmeter.

X-ray crystallography. Single crystals of the $\mathrm{M}\left(\kappa^{2}-\mathrm{bipy}\right)_{4}(\mathrm{M}=\mathrm{La}$ and $\mathrm{Ce})$ and $\left[\mathrm{Li}(\text { thf })_{4}\right]\left[\mathrm{Tb}\left(\kappa^{2} \text {-bipy }\right)_{4}\right]$ were coated in Paratone-N oil and mounted on a Kaptan loop. The loop was transferred to a Bruker SMART APEX, diffractometer equipped with a CCD area detector. ${ }^{41}$ Data were integrated by the program SAINT $^{42}$ to a maximum $2 \theta$ value of $50.74^{\circ}$ for $\mathrm{Ce}\left(\kappa^{2} \text {-bipy }\right)_{4}$, and $50.82^{\circ}$ for $\mathrm{La}\left(\kappa^{2} \text {-bipy }\right)_{4}$, and $\left[\mathrm{Li}(\mathrm{thf})_{4}\right]\left[\mathrm{Tb}\left(\kappa^{2}-\text { bipy }\right)_{4}\right]$. A semi-empirical multi-scan absorption correction was applied using SADABS. ${ }^{43}$ The structures were solved 
by direct methods using SHELX ${ }^{44}$ or SIR-97 and the WinGX program. ${ }^{45}$ Non-hydrogen atoms were refined anisotropically and hydrogen atoms were placed in calculated positions and not refined. The structures have been deposited to the CCDC with numbers \# 19141451914147 for $\mathrm{Ce}\left(\kappa^{2}-\text { bipy }\right)_{4}, \mathrm{La}\left(\kappa^{2}-\text { bipy }\right)_{4}$, and $\left[\mathrm{Li}(\mathrm{thf})_{4}\right]\left[\mathrm{Tb}\left(\kappa^{2}-\text { bipy }\right)_{4}\right]$, respectively.

\section{Syntheses.}

Synthesis of Cp3"Dy. In the glovebox, Dy(OTf) ${ }_{3}(6.29 \mathrm{~g}, 10.3 \mathrm{mmol})$ and $\mathrm{Cp}{ }_{2} \mathrm{Mg}(6.85$ $\mathrm{mg}, 15.5 \mathrm{mmol}$ ) were added to an oven-dried $250 \mathrm{ml}$ round-bottom Schlenk flask containing an oven-dried magnetic stirbar. On the benchtop, freshly distilled thf (150 ml) was added to the flask. The resultant mixture was stirred under an atmosphere of nitrogen at room temperature for $22 \mathrm{~h}$. During this time, the mixture gradually went from colorless to yellow. Afterward, the solvent was removed under reduced pressure, and the desired product was extracted with a single portion of freshly distilled pentane $(250 \mathrm{ml})$. The extraction was filtered through a glass fiber filter. The resultant clear, yellow filtrate was slightly concentrated under reduced pressure and chilled at $-20^{\circ} \mathrm{C}$ for $14 \mathrm{~h}$. Afterward, large, nicelyformed, vibrantly yellow crystals exposed to dynamic vaccum in a hot water bath for $1 \mathrm{~h}$ to give $3.60 \mathrm{~g}(44.1 \%)$ of $\mathrm{Cp}_{3}{ }_{3} \mathrm{Dy}\left(\mathrm{mp} .225-228^{\circ} \mathrm{C}\right)$. A second crop of $\mathrm{Cp}{ }_{3}{ }_{3} \mathrm{Dy}(504 \mathrm{mg}, 50.3 \%$ total) was obtained from the concentrated mother liquor. The $\mathrm{Cp}{ }_{3}{ }_{3} \mathrm{Dy}$ product is air sensitive; it goes from yellow to red upon air exposure. An attempt was made to obtain a ${ }^{1} \mathrm{H}$ NMR spectrum in $\mathrm{C}_{6} \mathrm{D}_{6}$, but no signals were observed. The product sublimed nicely when sealed in an ampule under moderate vacuum and heated to approximately $200^{\circ} \mathrm{C}$. IR $(\mathrm{KBr}$, Nujol, $\mathrm{cm}^{-1}$ ) v: 3089(s), 3057(s), 1459(s), 1439(s), 1400(s), 1377(s), 1320(s), 1244(s), 1206(s), 1181(s), 1078(s), 1058(s), 923(s), 831(s), 783(s), 749(s), 688(s), 642(s), 623(s).

Synthesis of Cp" ${ }_{3}$ La. In the glovebox, $\mathrm{La}(\mathrm{OTf})_{3}(5.00 \mathrm{~g}, 8.53 \mathrm{mmol})$ and Cp" ${ }_{2} \mathrm{Mg}(5.67 \mathrm{mg}$, $12.80 \mathrm{mmol}$ ) were added to an oven-dried $250 \mathrm{ml}$ round-bottom Schlenk flask containing an 
oven-dried magnetic stirbar. On the benchtop, freshly distilled thf $(150 \mathrm{ml})$ was added to the flask. The resultant mixture was stirred under an atmosphere of nitrogen at room temperature for $42 \mathrm{~h}$. Afterward, the solvent was removed under reduced pressure and the desired product was extracted with a single portion of freshly distilled pentane $(250 \mathrm{ml})$. The extract was filtered through a glass fiber filter. The resultant clear, yellow filtrate was slightly concentrated under reduced pressure and chilled at $-20^{\circ} \mathrm{C}$ for $3 \mathrm{~d}$. Afterward, nicely-formed, white block-like crystals were exposed to dynamic vaccum in a hot water bath for $1 \mathrm{~h}$ to give $1.95 \mathrm{~g}(30 \%)$ of $\mathrm{Cp}{ }_{3} \mathrm{La}\left(\mathrm{mp} .225-228^{\circ} \mathrm{C}\right)$. A second crop of Cp" ${ }_{3} \mathrm{La} \quad(3.20 \mathrm{mg}, 49 \%$ total $)$ was obtained from the concentrated mother liquor. ${ }^{1} \mathrm{H}$ NMR $\left(\mathrm{C}_{6} \mathrm{D}_{6}, 400 \mathrm{Mhz}, \delta\right.$ in ppm): 0.34 (s, $54 \mathrm{H}), 6.84(\mathrm{~d}, 6 \mathrm{H}), 6.90(\mathrm{t}, 3 \mathrm{H})$.

Synthesis of $\mathbf{C e}\left(\kappa^{2} \text {-bipy }\right)_{4}$ from $\mathrm{CeI}_{3}(\text { thf })_{3}$. On the benchtop, a single piece of Li wire (62.0 $\mathrm{mg}, 8.95 \mathrm{mmol}$ ) was wrapped around a small oven-dried magnetic stirbar. The Li/stirbar was added to an oven-dried Schlenk flask, exposed to dynamic vaccum, and then brought into the glovebox. In the glovebox, bipy (350 mg, $2.24 \mathrm{mmol})$ and $\mathrm{CeI}_{3}(\mathrm{thf})_{3}(500 \mathrm{mg}, 0.678 \mathrm{mmol})$ were added to the flask containing the Li/stirbar. The flask was returned to the benchtop, and freshly distilled thf $(30 \mathrm{ml})$ was added to it without stirring. The flask was put under an atmosphere of nitrogen and set in the fume hood at room-temperature away from sunlight and vibrations. The mixture was originally faintly yellow. Dark red plumes slowly began to form as Li(bipy) was generated in situ. The mixture was left undisturbed for $2 \mathrm{~d}$, after which time the mixture was uniformly an intensely dark red color. The mother liquor was removed and large black needles were obtained. The black needles were washed with 2 x $30 \mathrm{ml}$ portions of freshly distilled thf and exposed to dynamic vaccum in a hot water bath for $2 \mathrm{~h}$ to give 259 $\mathrm{mg}(50 \%)$ of $\mathrm{Ce}\left(\kappa^{2} \text {-bipy }\right)_{4}$. Note that some small chunks of $\mathrm{CeI}_{3}(\text { thf })_{3}$ were present. The $\mathrm{CeI}_{3}(\text { thf })_{3}$ starting material is only somewhat soluble in thf and therefore is an intractable impurity in the $\mathrm{Ce}\left(\kappa^{2} \text {-bipy }\right)_{4}$ product. The $\mathrm{Ce}\left(\kappa^{2} \text {-bipy }\right)_{4}$ product could not be studied by ${ }^{1} \mathrm{H}$ 
NMR or UV-Vis spectroscopy due to its insolubility in common solvents such as toluene, pentane, or thf. A single crystal of $\mathrm{Ce}\left(\kappa^{2} \text {-bipy }\right)_{4}$ was selected for X-ray crystallographic studies. $\mathrm{Ce}\left(\kappa^{2}-\text { bipy }\right)_{4}$ is highly air- and moisture-sensitive, going from intensely dark purple/black to white upon air- or moisture-exposure. IR (KBr, Nujol, $\left.\mathrm{cm}^{-1}\right)$ v: 1591(w), 1564(w), 1530(w), 1505(w), 1489(m), 1464(m), 1433(m), 1401(w), 1377(m), 1335(w), 1305(w), 1286(w), 1269(w), 1254(w), 1220(w), 1211(w), 1201(w), 1173(w), 1152(w), 1141(w), 1118(w), 1078(w), 1061(w), 1042(w), 1033(w), 1021(w), 1010(w), 998(w), 942(m), 886(w), 833(w), 802(w), 763(w), 746(w), 730(m), 721(m), 682(w), 669(w), 652(w), 636(w), 624(w), 599(w).

Synthesis of $\mathrm{Ce}\left(\kappa^{2} \text {-bipy }\right)_{4}(\text { thf })_{2}$ from Cp" ${ }_{3}$ Ce. To an oven-dried Schlenk flask were added $\mathrm{Cp}{ }_{3} \mathrm{Ce}(500 \mathrm{mg}, 0.651 \mathrm{mmol})$, bipy $(447 \mathrm{mg}, 2.86 \mathrm{mmol})$, and an oven-dried magnetic stirbar. The contents of the flask were dissolved in freshly distilled thf $(50 \mathrm{ml})$ to give a blue solution. A single piece of Li wire $(96.0 \mathrm{mg}, 13.8 \mathrm{mmol})$ was wrapped around an oven-dried magnetic stirbar and added to a second Schlenk flask, which was then exposed to dynamic vaccum for 30 minutes. The $\mathrm{Cp}_{3}{ }_{3} \mathrm{Ce}$ solution was filtered via filter cannula into the Schlenk flask containing the $\mathrm{Li} /$ stirbar. The $\mathrm{Li} /$ stirbar was kept above the solvent level using a strong magnet and the flask was set in the fridge at $-20^{\circ} \mathrm{C}$. After the solution had settled, the $\mathrm{Li} /$ stirbar was slowly lowered into the solution and gently positioned at the bottom of the flask using a strong magnet, as illustrated in Figure S4. After $2.5 \mathrm{~d}$, the mixture had gone from dark blue to intensely dark red. The flask was removed from the fridge, and the mother liquor was immediately removed via cannula to reveal a black crystalline product. The product was washed with $4 \times 40 \mathrm{ml}$ portions of freshly distilled thf. The fourth washing was colorless. The product was then washed with 2 x $30 \mathrm{ml}$ portions of freshly distilled pentane in order to remove residual thf and facilitate drying. The flask containing the product was put in a warm water bath, fitted with a septum with a small needle exit, and flushed with nitrogen 
for $2 \mathrm{~h}$ in order to dry the product. $\mathrm{Ce}\left(\kappa^{2}-\text { bipy }\right)_{4}(\mathrm{thf})_{2}$ was obtained in $273 \mathrm{mg}(46 \%)$ yield. $\mathrm{Ce}\left(\kappa^{2} \text {-bipy }\right)_{4}(\mathrm{thf})_{2}$ is insoluble in DCM and thf and rapidly goes from black to white upon trace amounts of air- or moisture-exposure. Elemental Analysis [Calcd. (Found)]: C, 63.41 (62.61); H, 5.32 (5.20); N, 12.33 (12.01). In a Li flame test, the $\mathrm{Ce}\left(\kappa^{2} \text {-bipy }\right)_{4}(\text { thf })_{2}$ product caused the flame to turn slightly scarlet. Perhaps trace amounts of $\mathrm{Li}$ are present. IR ( $\mathrm{KBr}$, Nujol, $\left.\mathrm{cm}^{-1}\right) v:$ 1587(w), 1564(w), 1530(w), 1505(m), 1489(m), 1463(s), 1402(m), 1377(m), 1336(m), 1305(w), 1285(w), 1267(m), 1256(m), 1220(w), 1201(m), 1140(m), 1111(w), 1078(m), 1041(w), 1022(m), 1011(m), 987(w), 946(m), 886(w), 824(w), 803(w), 745(w), $729(\mathrm{~m}), 721(\mathrm{~m}), 680(\mathrm{~m}) 664(\mathrm{w}), 636(\mathrm{~m}), 599(\mathrm{~m})$. These data are in agreement with those from the synthesis of $\mathrm{Ce}\left(\kappa^{2}-\text { bipy }\right)_{4}$ from $\mathrm{CeI}_{3}(\text { thf })_{3}$.

Synthesis of Ce( $\boldsymbol{\kappa}^{2}$-bipy $)_{4}(\mathbf{t h f})$. A single piece of Li wire (200 mg, $\left.28.8 \mathrm{mmol}\right)$ was wrapped around an oven-dried magnetic stirbar and added to an oven-dried Schlenk flask. The contents of the flask were exposed to dynamic vaccum in the glovebox antechamber. In the glovebox, large blue crystals of $\mathrm{Cp}{ }_{3} \mathrm{Ce}(1.00 \mathrm{~g}, 0.651 \mathrm{mmol})$ and bipy $(1.20 \mathrm{~g}, 7.68 \mathrm{mmol})$ were added to the flask. On the benchtop, The Li/stirbar was kept at the top of the flask using a strong magnet, as illustrated in Figure S4. Freshly distilled thf $(150 \mathrm{ml})$ was added to the flask, giving a blue solution. The flask was put under an atmosphere of nitrogen and set in the fume hood at room-temperature. The Li/stirbar was then gently lowered into the solution and positioned at the bottom of the flask using a strong magnet. Dark red plumes began to form. The flask sat undisturbed for $22 \mathrm{~h}$, and the reaction mixture became uniformly dark red. The mother liquor was removed via filter cannula to give small black crystals, which were washed with 3 x $40 \mathrm{ml}$ portions of freshly distilled thf. The $\mathrm{Ce}\left(\kappa^{2}-\text { bipy }\right)_{4}(\mathrm{thf})$ product is insoluble in thf, but it can give a dark fine suspension. The product was dried in a hot water bath by flushing nitrogen through the flask, which had been fitted with a septum punctured by a small needle. Shiny black crystals of Ce( $\kappa^{2}$-bipy) $)_{4}($ thf $)$ were obtained in $404 \mathrm{mg}$ (37\%) yield. The 
black product decomposes and turns white upon trace amounts of air- or moisture-exposure. Elemental Analysis [Calcd. (Found)]: C, 63.14 (62.26); H, 4.82 (4.80); N, 13.39 (13.16). In a Li flame test, the $\mathrm{Ce}\left(\kappa^{2} \text {-bipy }\right)_{4}($ thf $)$ product caused the flame to turn slightly scarlet. Perhaps trace amounts of $\mathrm{Li}$ are present. IR (KBr, Nujol, $\left.\mathrm{cm}^{-1}\right) v$ : 1586(w), 1561(w), 1529(m), 1505(w), 1488(m), 1463(m), 1400(w), 1377(m), 1335(w), 1304(w), 1292(w), 1284(w), 1267(w), 1255(w), 1220(w), 1200(w), 1152(w), 1140(w), 1110(w), 1099(w), 1077(w), 1061(w), 1042(w), 1021(w), 1011(w), 986(w), 947(w), 938(w), 894(w), 885(w), 800(w), 762(w), 751(w), 746(w), 729(m), 720(m), 689(w), 680(w), 635(w), 598(w).

Synthesis of $\mathbf{L a}\left(\boldsymbol{\kappa}^{2}-\mathbf{b i p y}\right)_{4}(\mathbf{t h f})$. In the glovebox, Cp" ${ }_{3} \mathrm{La}(975 \mathrm{mg}, 1.27 \mathrm{mmol})$ and bipy (1.03 $\mathrm{mg}, 6.59 \mathrm{mmol})$ were added to an Schlenk flask. On the benchtop, a single piece of Li wire (151 mg, $21.8 \mathrm{mmol})$ was wrapped around a magnetic stirbar, added to a second Schlenk flask and pumped under reduced pressure for $40 \mathrm{~min}$. The Li/stirbar was quickly transferred to the Schlenk containing the lanthanum stating material under a nitrogen flow and the Li/stirbar was maintained at the top of the flask using a strong magnet. Freshly distilled thf (50-60 mL) was added to the flask, giving a clear faintly yellow solution. Most of the solid went into solution immediately. The mixture was not stirred. The flask was put under a nitrogen atmosphere and gently set in the fume hood away from light. The Li/stirbar was then gently lowered into the solution and positioned at the bottom of the flask using a strong magnet. Dark red plumes immediately began to appear, indicating that Li(bipy) was forming in situ. The flask was let undisturbed for $23 \mathrm{~h}$, after which the mixture was uniformly dark red. The mother liquor was removed via cannula, leaving behind black needle-like crystals of $\mathrm{La}\left(\kappa^{2} \text {-bipy }\right)_{4}$. The crystals were washed with three times with $30 \mathrm{~mL}$ of thf and the product was dried in a warm water bath for $2 \mathrm{~h}$, flushing nitrogen through the flask. The $\mathrm{La}\left(\kappa^{2} \text {-bipy }\right)_{4}(\mathrm{thf})$ was obtained in $584 \mathrm{mg}(55 \%)$ yield. $\mathrm{mp}>340{ }^{\circ} \mathrm{C}$. Elemental Analysis [Calculated (Found)]: C, 63.52 (61.50); H, 4.82 (4.66); N, 13.41 (13.30). In a Li flame test, 
the $\mathrm{La}\left(\kappa^{2} \text {-bipy }\right)_{4}($ thf $)$ product caused the flame to turn slightly scarlet. Perhaps trace amounts of $\mathrm{Li}$ are present. (KBr, Nujol, $\left.\mathrm{cm}^{-1}\right) v: 1586(\mathrm{w}), 1564(\mathrm{w}), 1529(\mathrm{~m}), 1504(\mathrm{~m}), 1487(\mathrm{~s}, \mathrm{sh})$, 1464(vs), 1403(w), 1377(s), 1337(w), 1304(vw), 1285(w), 1266(m, sh), 1257(m), 1219(vw), 1200(m), 1160(w), 1110(w), 1140(m), 1077(w), 1039(w), 1021(w), 1011(m), 987(m), 939(s), 884(vw), 801(m), 762(w), 745(w), 720(s), 679(m), 669(w), 635(m), 598(w).

Synthesis of $\mathbf{L a}\left(\kappa^{2}-\text { bipy }\right)_{4}$. When the same procedure for $\mathrm{La}\left(\kappa^{2}-\text { bipy }\right)_{4}($ thf $)$ was performed with $\mathrm{Et}_{2} \mathrm{O}$ instead of thf, the base-free $\mathrm{La}\left(\kappa^{2}-\text { bipy }\right)_{4}$ complex is obtained in low yield $(8 \%)$. Elemental Analysis [Calculated (Found)]: C, 62.91 (63.07); H, 4.22 (4.53); N, 14.68 (15.30).

Synthesis of $\left[\mathbf{L i}(\mathbf{t h f})_{4}\right]\left[\mathbf{D y}\left(\boldsymbol{\kappa}^{2} \text {-bipy }\right)_{4}\right]$. A single piece of Li wire $(146 \mathrm{mg}, 21.0 \mathrm{mmol})$ was wrapped around an oven-dried magnetic stirbar, added to an oven-dried Schlenk flask, and exposed to a dynamic vaccum in the antechamber of the glovebox. In the glovebox, $\mathrm{Cp}$ " 3 Dy $(1.05 \mathrm{~g}, 1.33 \mathrm{mmol})$ and bipy $(1.20 \mathrm{~g}, 7.68 \mathrm{mmol})$ were added to the flask. On the benchtop, the Li/stirbar was kept at the top of the flask above the solid. (See Figure S4) Freshly distilled thf $(150 \mathrm{ml})$ was added to the flask, giving a yellow solution. The flask was put under an atmosphere of nitrogen and set in a fume hood away from sunlight and vibration. The $\mathrm{Li} /$ stirbar were gently lowered into the solution and gently positioned at the bottom of flask, and dark red plumes began to form. The mixture sat for $16 \mathrm{~h}$ at room-temperature, during which time the mixture became uniformly dark red. The mother liquor was then removed by cannula to give black block-like crystals along with some long needles. The product was washed several times with chilled thf since the product appears to be somewhat soluble in thf. The product was dried by flushing it with nitrogen in a hot water bath for $1 \mathrm{~h}$ to yield $815 \mathrm{mg}$ $(59 \%)$ of $\left[\operatorname{Li}(\operatorname{thf})_{4}\right]\left[\mathrm{Dy}\left(\kappa^{2}-\text { bipy }\right)_{4}\right]$. A crystal structure could not be obtained since the crystals were twinned. Elemental Analysis [Calculated (Found)]: C, 62.12 (62.22); H, 5.96 (5.77); $10.35(10.48)$. The $\left[\operatorname{Li}(\operatorname{thf})_{4}\right]\left[\mathrm{Dy}\left(\kappa^{2} \text {-bipy }\right)_{4}\right]$ product is somewhat soluble in thf and highly 
soluble in pyridine.

$\left[\mathrm{Li}(\mathrm{thf})_{4}\right]\left[\mathrm{Dy}\left(\kappa^{2}-\text { bipy }\right)_{4}\right]$ is highly soluble in pyridine, giving an intensely dark red solution. A ${ }^{1} \mathrm{H}$ NMR sample was prepared by dissolving a $30 \mathrm{mg}$ sample of $\left[\operatorname{Li}(\operatorname{thf})_{4}\right]\left[\mathrm{Dy}\left(\kappa^{2}-\text { bipy }\right)_{4}\right]$ in roughly $0.7 \mathrm{ml}$ of pyridine- $\mathrm{d}_{5}$. A ${ }^{1} \mathrm{H}$ NMR sample was obtained at $400 \mathrm{MHz}$ at $293.9 \mathrm{~K}$ $\left(\delta / \mathrm{ppm}, \mathrm{C}_{5} \mathrm{D}_{5} \mathrm{~N}\right)$ : -171.81 (broad singlet, $\left.6.3 \mathrm{H}\right),-145.24$ (very broad singlet, 4.2 H), -57.24 (broad singlet, $6.0 \mathrm{H}$ ), 1.55 (m, $16 \mathrm{H}$, thf), 3.67 (m, $16 \mathrm{H}$, thf), 20.74 (broad singlet, 6.3H). A granule of sublimed bipy was added to the sample, and a new ${ }^{1} \mathrm{H}$ NMR spectrum was obtained ( $\left.\delta / \mathrm{ppm}, \mathrm{C}_{5} \mathrm{D}_{5} \mathrm{~N}\right)$ : -170.86 (broad singlet, $6.1 \mathrm{H}$ ), -147.09 (very broad singlet, $4.2 \mathrm{H}$ ), $1.54(\mathrm{~m}, 16 \mathrm{H}$, thf), $3.66(\mathrm{~m}, 16 \mathrm{H}$, thf), 21.25 (broad singlet, $5.5 \mathrm{H}$ ). There is also a new broad mound between $\delta 0-20 \mathrm{ppm}$. A few more granules of bipy were added to the sample, and a new ${ }^{1} \mathrm{H}$ NMR spectrum was obtained $\left(\delta / \mathrm{ppm}, \mathrm{C}_{5} \mathrm{D}_{5} \mathrm{~N}\right)$ : -168.09 (broad singlet, $\left.5.8 \mathrm{H}\right)$, 147.85 (very broad singlet, $3.2 \mathrm{H}$ ), -58.34 (broad singlet, $5.7 \mathrm{H}), 1.56(\mathrm{~m}, 16 \mathrm{H}$, thf), 3.66 (m, $16 \mathrm{H}$, thf), 9.74 (broad singlet), 22.52 (broad singlet, $4.7 \mathrm{H}$ ). The shifts change slightly compared to the case without added free bipy. However, the broad mound at $\delta 9.74 \mathrm{ppm}$ indicates that the added free bipy is undergoing an exchange process with $\left[\mathrm{Li}(\operatorname{thf})_{4}\right]\left[\mathrm{Dy}\left(\kappa^{2}-\right.\right.$ bipy $)_{4}$ ]. IR specrum: (KBr, Nujol, $\left.\mathrm{cm}^{-1}\right)$ v: 3099(w), 3046(w), 1568(w), 1566(w), 1536(w), 1485(s), 1464(s), 1409(m), 1377(m), 1352(w), 1342(w), 1288(w), 1265(m), 1257(m), 1203(m), 1168(w), 1139(m), 1113(w), 1080(w), 1040(m), 1013(m), 991(m), 945(m), 884(w), 801(w), 745(w), 715(m), 704(w), 680(m), 637(m), 601(w).

Synthesis of $\left[\mathbf{L i}(\mathbf{t h f})_{4}\right]\left[\mathbf{T b}\left(\kappa^{2} \text {-bipy }\right)_{4}\right]$. A single piece of Li wire $(205 \mathrm{mg}, 29.5 \mathrm{mmol})$ was wrapped around an oven-dried magnetic stirbar and added to an oven-dried Schlenk flask. The flask was promptly exposed under vacuum in the glovebox antechamber. In the glovebox, $\mathrm{Cp}_{3}{ }_{3} \mathrm{~Tb}(1.00 \mathrm{~g}, 2.52 \mathrm{mmol})$ and sublimed bipy $(1.90 \mathrm{~g}, 12.2 \mathrm{mmol})$ were added to the flask. Using a strong magnet, the Li/stirbar was kept at the top of the flask. Freshly distilled thf $(150 \mathrm{ml})$ was added to the flask, and nearly all of the $\mathrm{Cp}_{3}{ }_{3} \mathrm{~Tb}$ and bipy had 
dissolved to give a faintly yellow solution. (See Figure S4) The resultant solution was put under an atmosphere of nitrogen, set in the fume hood away from sunlight and vibration, and allowed to settle. The Li/stirbar was gently lowered into the reaction mixture and positioned at the bottom of the flask. Dark red plumes began to form slowly and diffuse throughout the mixture. The mixture sat under nitrogen at room-temperature for $24 \mathrm{~h}$, giving a uniformly dark red mixture. The dark red mother liquor was removed by cannula filtration, leaving behind black crystals. The crystalline product was washed several times with freshly distilled and dried in a hot water bath by flushing nitrogen through the flask for $2 \mathrm{~h}$ to give $138 \mathrm{mg}$ $(5 \%)$ of $\left[\mathrm{Li}(\operatorname{thf})_{4}\right]\left[\mathrm{Tb}\left(\kappa^{2}-\text { bipy }\right)_{4}\right]$. The mother liquor was allowed to sit undisturbed on the benchtop at room-temperature to give a second crop of $\left[\mathrm{Li}(\mathrm{thf})_{4}\right]\left[\mathrm{Tb}\left(\kappa^{2} \text {-bipy }\right)_{4}\right]$. to give a total yield of $256 \mathrm{mg}$ (9\%). Elemental Analysis [Calcd. (Found)]: C, 62.33 (61.63); H, 5.98 (5.92); 10.39 (10.14). A single crystal of $\left[\mathrm{Li}(\text { thf })_{4}\right]\left[\mathrm{Tb}\left(\kappa^{2}-\text { bipy }\right)_{4}\right]$. was selected for X-ray crystallographic studies.

$\left[\mathrm{Li}(\text { thf })_{4}\right]\left[\mathrm{Tb}\left(\kappa^{2}-\text { bipy }\right)_{4}\right]$ is highly soluble in pyridine, giving an intensely dark red solution. A ${ }^{1} \mathrm{H}$ NMR spectrum was obtained at $400 \mathrm{MHz}$ and $293.9 \mathrm{~K}\left(\mathrm{C}_{5} \mathrm{D}_{5} \mathrm{~N}, \delta / \mathrm{ppm}\right):-188.02$ (very broad singlet, 1.4 H), -181.71 (broad singlet, 3.9 H), -56.89 (broad singlet, 4.5 H), 1.59 (m, thf, $16.0 \mathrm{H}), 3.66(\mathrm{~m}$, thf, $16.0 \mathrm{H}), 30.95$ (broad singlet, 4.2 H). The NMR sample was hydrolyzed using a small amount of degassed $\mathrm{D}_{2} \mathrm{O}$, and the dark red solution immediately became clear and colorless. The sample was promptly filtered through a glass fiber filter, and a ${ }^{1} \mathrm{H}$ NMR spectrum (400 MHz, $\mathrm{C}_{5} \mathrm{D}_{5} \mathrm{~N}$ ) was obtained within minutes of hydrolysis. The spectrum is clean and clearly shows that free bipy, bipyH $\mathrm{H}_{2}$, and thf are present in the sample. Compared to the four equivalents of thf, the relative integrals of the shifts indicate that two equivalents of free bipy and one equivalent of hydrolyzed bipy radical anion are present in solution. Therefore, for reasons which are uncertain, one equivalent of bipy is missing from the spectrum. FTIR (KBr, Nujol, $\left.\mathrm{cm}^{-1}, \mathrm{ID}=9608112011\right)$ v: 3097(w), 3046(w), 1567(w), 
1552(w), 1547(w), 1536(w), 1518(vw), 1509(w), 1485(s), 1463(s), 1409(m), 1377(s), 1352(m), 1288(w), 1266(m), 1256(m), 1203(m), 1168(w), 1148(m), 1140(m), 1113(m), 1080(w), 1040(m), 1013(m), 992(m), 946(s), 885(w), 817(vw), 801(vw), 774(vw), 746(w), 724(m), 715(m), 704(w), 681(m).

${ }^{1}$ H NMR Spectroscopy hydrolysis studies. The $\mathrm{Ce}\left(\kappa^{2}-\text { bipy }\right)_{4}(\text { thf })_{2}$ product is insoluble in $\mathrm{C}_{6} \mathrm{D}_{6}$ and thf- $\mathrm{d}_{8}$. A sample of $\mathrm{Ce}\left(\kappa^{2}-\text { bipy }\right)_{4}(\text { thf })_{2}$ was suspended in $\mathrm{C}_{6} \mathrm{D}_{6}$ and hydrolyzed with degassed $\mathrm{D}_{2} \mathrm{O}$. The dark red suspension became pale yellow, and a fine white solid formed. A ${ }^{1}$ H NMR spectrum was obtained within 20 minutes of hydrolysis. The spectrum only showed free thf, free bipy, and hydrolyzed bipyridyl radical anion, referred as bipyH $\mathrm{H}_{2}$. In the spectrum, the shimming is slightly off because the fine white solid formed from hydrolysis gave a fine suspension. The hydrolyzed ${ }^{1} \mathrm{H}$ NMR sample sat on the benchtop for $24 \mathrm{~h}$ and settled. A new ${ }^{1} \mathrm{H}$ NMR spectrum of the sample was obtained. The spectrum is clean, and each shift has well-resolved splitting. The spectrum clearly shows shifts corresponding to free thf, free bipy, and bipyH $\mathrm{H}_{2}$. The relative integrations of these shifts support the notion that the product is indeed $\mathrm{Ce}\left(\mathrm{k}^{2} \text {-bipy }\right)_{4}(\mathrm{thf})_{2}$. Over time, the shifts corresponding to bipyH $\mathrm{H}_{2}$ shrink while the shifts corresponding to free bipy grow. A ${ }^{2} \mathrm{H}$ NMR $\left(\mathrm{C}_{6} \mathrm{D}_{6}\right)$ spectrum was also obtained $24 \mathrm{~h}$ after hydrolysis. A doublet was observed between 3.07-3.16 ppm) that corresponds to bipyH $\mathrm{H}_{2}$

An attempt was made to prepare a ${ }^{1} \mathrm{H}$ NMR sample of $\mathrm{Ce}\left(\mathrm{k}^{2}-\text { bipy }\right)_{4}(\mathrm{thf})_{2}$ in pyridine- $\mathrm{d}_{5}$. Pyridine- $\mathrm{d}_{5}$ was added to a sample of $\mathrm{Ce}\left(\mathrm{k}^{2} \text {-bipy }\right)_{4}(\text { thf })_{2}$, giving a black/purple mixture. $\mathrm{Ce}\left(\mathrm{k}^{2} \text {-bipy }\right)_{4}(\mathrm{thf})_{2}$ appeared to be sparingly soluble in pyridine. The mixture was filtered using a glass fiber filter, and a ${ }^{1} \mathrm{H}$ NMR spectrum was obtained (pyridine- $\mathrm{d}_{5}, \delta / \mathrm{ppm}$ ): -75.75 $(\mathrm{s}, 0.35 \mathrm{H}) ;-18.59(\mathrm{~s}, 0.44 \mathrm{H}) ; 1.62(\mathrm{~m}, 8 \mathrm{H}$, thf); $3.66(\mathrm{~m}, 8 \mathrm{H}$, thf); $10.83(\mathrm{~s}, 0.43 \mathrm{H})$. Between 0-10 ppm, there are small shifts corresponding to $\operatorname{bipyH}_{2}$, indicating that a trace of $\mathrm{H}_{2} \mathrm{O}$ is present in the pyridine- $\mathrm{d}_{5}$. After $24 \mathrm{~h}$ the shifts outside of 0-10 ppm had disappeared. 
It is likely that trace $\mathrm{H}_{2} \mathrm{O}$ in the pyridine- $\mathrm{d}_{5}$ hydrolyzed whatever gave rise to the shifts outside of 0-10 ppm. 


\section{ASSOCIATED CONTENT}

Supporting Information. X-ray data, synthetic details, EPR and magnetic measurements data as well as coordinates for the computed molecules can be found in the supporting information. An overall CIF file for the X-ray structures of $\mathrm{Ce}\left(\kappa^{2}-\text { bipy }\right)_{4}, \mathrm{La}\left(\kappa^{2}-\text { bipy }\right)_{4}$, and $\left[\mathrm{Li}(\text { thf })_{4}\right]\left[\mathrm{Tb}\left(\kappa^{2}-\text { bipy }\right)_{4}\right]$ is also given in supporting information.

\section{AUTHOR INFORMATION}

\section{Corresponding Author}

* greg.nocton@polytechnique.edu (GN)

* raandersen@lbl.gov (RAA)

\section{ACKNOWLEDGMENT}

GN thanks the CNRS and Ecole polytechnique for funding. Work at the University of California, Berkeley, and at Lawrence Berkeley National Laboratory was supported by the Director, Office of Energy Research, Office of Basic Energy Sciences, Chemical Sciences, Geosciences and Biosciences Division, Heavy Element Chemistry Program, of the U.S. Department of Energy under Contract No. DE-AC02-05CH11231. Use of the Stanford Synchrotron Radiation Lightsource, SLAC National Accelerator Laboratory, is supported by the U.S. Department of Energy, Office of Science, Office of Basic Energy Sciences under Contract No. DE-AC02-76SF00515. We thank T. Cheisson for calculating the shape parameters and M. D. Walter for the magnetic susceptibility measurements for $\left[\mathrm{M}\left(\kappa^{2}-\text { bipy }\right)_{4}\right]$ $\mathrm{M}=\mathrm{Eu}$ and $\mathrm{Yb}$. L.M. is a member of the Institut Universitaire de France. Cines and CALMIP are acknowledged for a generous grant of computing time. L.M. also thanks the Humboldt Foundation for a fellowship. 


\section{REFERENCES}

1. Herzog S.; Gustav, K., Über einen elektronenreichen Komplex des Lanthans mit 2,2'-Dipyridyl: LaDipy4. Z. Anorg. Allg. Chem. 1966, 346, 162-165.

2. Herzog, S.; Schuster, R., ZUR DARSTELLUNG ELEKTRONENREICHER VERBINDUNGEN DER LANTHANIDENELEMENTE CER NEODYM UND YTTERBIUM MIT 2,2'-DIPYRIDYL. Z. Chem. 1967, 7, 26.

3. Siegfried, H.; Rudolf, T., Neutralkomplexe des 2,2'-Dipyridyls Teil I Darstellung und Eigenschaften. Z. Chem. 1962, 2, 208-214.

4. Feistel, G. R.; Mathai, T. P., A new type of intramolecular antiferromagnetism. J. Am. Chem. Soc. 1968, 90, 2988-2989.

5. Fedushkin, I. L.; Petrovskaya, T. V.; Girgsdies, F.; Nevodchikov, V. I.; Weimann, R.; Schumann, H.; Bochkarev, M. N., Synthesis and properties of homoleptic 2,2 '-bipyridyl complexes of rare-earth elements. Crystal and molecular structures of the complexes $\mathrm{Ln}(\mathrm{N} 2 \mathrm{C} 10 \mathrm{H} 8)(4)(\mathrm{Ln}=\mathrm{Sm}, \mathrm{Eu}, \mathrm{Yb}$, or $\mathrm{Lu})$ and the ionic complex $\mathrm{Lu}(\mathrm{N} 2 \mathrm{C} 10 \mathrm{H} 8)(4)$ Li(THF)(4). Russ. Chem. Bull. 2000, 49, 1869-1876.

6. Pappalardo, R., Absorption spectra of neutral dipyridyl complexes. Inorg. Chim. Acta 1968, 2, 209-215.

7. Fedushkin, I. L.; Dechert, S.; Schumann, H., Organometallic compounds of the lanthanides. 141. Synthesis, molecular structure, and solution behavior of some lanthanum(III) and ytterbium(II) complexes containing new tridentate 1,2 and 1,3-bis (2(dimethylamino)ethyl) cyclopentadienyl ligands. Organometallics 2000, 19, 4066-4076.

8. Bowman, A. C.; England, J.; Sproules, S.; Weyhermüller, T.; Wieghardt, K., Electronic Structures of Homoleptic [Tris(2,2'-bipyridine)M]n Complexes of the Early Transition Metals ( $\left.\mathrm{M}=\mathrm{Sc}, \mathrm{Y}, \mathrm{Ti}, \mathrm{Zr}, \mathrm{Hf}, \mathrm{V}, \mathrm{Nb}, \mathrm{Ta} ; \mathrm{n}=1+, 0,1-, 2-, 3^{-}\right)$: An Experimental and Density Functional Theoretical Study. Inorg. Chem. 2013, 52, 2242-2256. 
9. Saito, Y.; Takemoto, J.; Hutchinson, B.; Nakamoto, K., Infrared studies of coordination compounds containing low-oxidation-state metals. I. Tris(2,2'-bipyridine) and tris(1,10-phenanthroline) complexes. Inorg. Chem. 1972, 11, 2003-2011.

10. Gore-Randall, E.; Irwin, M.; Denning, M. S.; Goicoechea, J. M., Synthesis and Characterization of Alkali-Metal Salts of 2,2'- and 2,4'-Bipyridyl Radicals and Dianions. Inorg. Chem. 2009, 48, 8304-8316.

11. Schultz, M.; Boncella, J. M.; Berg, D. J.; Tilley, T. D.; Andersen, R. A., Coordination of 2,2 '-bipyridyl and 1,10-phenanthroline to substituted ytterbocenes: An experimental investigation of spin coupling in lanthanide complexes. Organometallics 2002, 21, 460-472.

12. Da Re, R. E.; Kuehl, C. J.; Brown, M. G.; Rocha, R. C.; Bauer, E. D.; John, K. D.; Morris, D. E.; Shreve, A. P.; Sarrao, J. L., Electrochemical and spectroscopic characterization of the novel charge-transfer ground state in diimine complexes of ytterbocene. Inorg. Chem. 2003, 42, 5551-5559.

13. Gil, V. M. S., RELATIVE SIGNS OF PROTON COUPLING CONSTANTS IN PYRIDINE RING-NMR SPECTRUM OF 2,2'-DIPYRIDINE. Mol. Phys/ 1965, 9, 97.

14. Kramer, F. A.; West, R., PROTON NUCLEAR MAGNETIC RESONANCE SPECTRUM OF 2,2'-BIPYRIDINE. J. Phys. Chem. 1965, 69, 673.

15. Creutz, C., Bipyridine Radical Ions. Comment. Inorg. Chem. 1982, 1, 293-311.

16. Chisholm, M. H.; Huffman, J. C.; Rothwell, I. P.; Bradley, P. G.; Kress, N.; Woodruff, W. H., Bis(2,2'-bipyridyl)diisopropoxymolybdenum(II). Structural and spectroscopic evidence for molybdenum-to-bipyridyl .pi.* bonding. J. Am. Chem. Soc. 1981, $103,4945-4947$.

17. Booth, C. H.; Walter, M. D.; Daniel, M.; Lukens, W. W.; Andersen, R. A., Selfcontained Kondo effect in single molecules. Phys. Rev. Lett. 2005, 95. 
18. Booth, C. H.; Walter, M. D.; Kazhdan, D.; Hu, Y.-J.; Lukens, W. W.; Bauer, E. D.; Maron, L.; Eisenstein, O.; Andersen, R. A., Decamethylytterbocene Complexes of Bipyridines and Diazabutadienes: Multiconfigurational Ground States and Open-Shell Singlet Formation. J. Am. Chem. Soc. 2009, 131, 6480-6491.

19. Muetterties, E. L.; Guggenberger, L. J., Idealized polytopal forms. Description of real molecules referenced to idealized polygons or polyhedra in geometric reaction path form. $J$. Am. Chem. Soc. 1974, 96, 1748-1756.

20. Fortier, S.; Veleta, J.; Pialat, A.; Le Roy, J.; Ghiassi, K. B.; Olmstead, M. M.; MettaMagaña, A.; Murugesu, M.; Villagrán, D., [U(bipy)4]: A Mistaken Case of U0? Chem. Eur. J. 2016, 22 (6), 1931-1936.

21. Shannon, R., Revised effective ionic radii and systematic studies of interatomic distances in halides and chalcogenides. Acta Crystallogr. A 1976, 32, 751-767.

22. Rahm, M.; Zeng, T.; Hoffmann, R., Electronegativity Seen as the Ground-State Average Valence Electron Binding Energy. J. Am. Chem. Soc. 2019, 141, 342-351.

23. Scarborough, C. C.; Wieghardt, K., Electronic Structure of 2,2, $\ddot{\mathrm{A}} \leq$-Bipyridine Organotransition-Metal Complexes. Establishing the Ligand Oxidation Level by Density Functional Theoretical Calculations. Inorg. Chem. 2011, 50, 9773-9793.

24. England, J.; Bill, E.; Weyhermuller, T.; Neese, F.; Atanasov, M.; Wieghardt, K., Molecular and Electronic Structures of Homoleptic Six-Coordinate Cobalt(I) Complexes of 2,2 ':6 ',2 "-Terpyridine, 2,2 '-Bipyridine, and 1,10-Phenanthroline. An Experimental and Computational Study. Inorg. Chem. 2015, 54, 12002-12018.

25. Wolff, C.; Gottschlich, A.; England, J.; Wieghardt, K.; Saak, W.; Haase, D.; Beckhaus, R., Molecular and Electronic Structures of Mononuclear and Dinuclear Titanium Complexes Containing pi-Radical Anions of 2,2 '-Bipyridine and 1,10-Phenanthroline: An Experimental and DFT Computational Study. Inorg. Chem. 2015, 54, 4811-4820. 
26. Halbach, R. L.; Nocton, G.; Booth, C. H.; Maron, L.; Andersen, R. A., Cerium Tetrakis(tropolonate) and Cerium Tetrakis(acetylacetonate) Are Not Diamagnetic but Temperature-Independent Paramagnets. Inorg. Chem. 2018, 57, 7290-7298.

27. Halbach, R. L.; Nocton, G.; Booth, C. H.; Maron, L.; Andersen, R. A., Correction to Cerium Tetrakis(tropolonate) and Cerium Tetrakis(acethylacetonate) Are Not Diamagnetic but Temperature-Independent Paramagnets. Inorg. Chem. 2018, 57, 8692-8692.

28. Dolg, M.; Fulde, P.; Kuchle, W.; Neumann, C. S.; Stoll, H., Ground-State Calculations of Di-Pi-Cyclooctatetraene Cerium. J. Chem. Phys. 1991, 94, 3011-3017.

29. Dolg, M.; Fulde, P.; Stoll, H.; Preuss, H.; Chang, A.; Pitzer, R. M., Formally Tetravalent Cerium and Thorium Compounds - a Configuration-Interaction Study of Cerocene $\mathrm{Ce}(\mathrm{C} 8 \mathrm{~h} 8)(2)$ and Thorocene $\mathrm{Th}(\mathrm{C} 8 \mathrm{~h} 8)(2)$ Using Energy-Adjusted QuasiRelativistic Ab-Initio Pseudopotentials. Chem. Phys. 1995, 195, 71-82.

30. Mooßen, O.; Dolg, M., Two interpretations of the cerocene electronic ground state. Chem. Phys. Lett. 2014, 594, 47-50.

31. Walter, M. D.; Booth, C. H.; Lukens, W. W.; Andersen, R. A., Cerocene Revisited: The Electronic Structure of and Interconversion Between Ce-2(C8H8)(3) and $\mathrm{Ce}(\mathrm{C} 8 \mathrm{H} 8)(2)$. Organometallics 2009, 28, 698-707.

32. Booth, C. H.; Kazhdan, D.; Werkema, E. L.; Walter, M. D.; Lukens, W. W.; Bauer, E. D.; Hu, Y.-J.; Maron, L.; Eisenstein, O.; Head-Gordon, M.; Andersen, R. A., IntermediateValence Tautomerism in Decamethylytterbocene Complexes of Methyl-Substituted Bipyridines. J. Am. Chem. Soc. 2010, 132, 17537-17549.

33. Nocton, G.; Booth, C. H.; Maron, L.; Andersen, R. A., Thermal Dihydrogen Elimination from $\mathrm{Cp} 2 * \mathrm{Yb}(4,5$-diazafluorene). Organometallics 2013, 32, 1150-1158. 
34. Nocton, G.; Booth, C. H.; Maron, L.; Andersen, R. A., Influence of the Torsion Angle in 3,3'-Dimethyl-2,2'-bipyridine on the Intermediate Valence of $\mathrm{Yb}$ in (C5Me5)2 $\mathrm{Yb}\left(3,3^{\prime}-\right.$ Me2-bipy). Organometallics 2013, 32, 5305-5312.

35. Nocton, G.; Booth, C. H.; Maron, L.; Ricard, L.; Andersen, R. A., Organometallics 2014, 44, 6819-6829.

36. Nocton, G.; Lukens, W. L.; Booth, C. H.; Rozenel, S. S.; Melding, S. A.; Maron, L.; Andersen, R. A., J. Am. Chem. Soc. 2014, 136, 8626-8641.

37. Goudy, V.; Jaoul, A.; Cordier, M.; Clavaguéra, C.; Nocton, G., Tuning the Stability of Pd(IV) Intermediates Using a Redox Non-innocent Ligand Combined with an Organolanthanide Fragment. J. Am. Chem. Soc. 2017, 139, 10633-10636.

38. Milko, P.; Iron, M. A., On the Innocence of Bipyridine Ligands: How Well Do DFT Functionals Fare for These Challenging Spin Systems? J. Chem. Theory Comput. 2014, 10, $220-235$.

39. Sofield, C. D.; Andersen, R. A., A GENERAL-SYNTHESIS AND CRYSTALSTRUCTURE OF [(ME(3)C)(2)C5H3]CE-3. J. Organomet. Chem. 1995, 501, 271-276.

40. Walter, M. D.; Schultz, M.; Andersen, R. A., Weak paramagnetism in compounds of the type CP' Yb-2(bipy). New J. Chem. 2006, 30, 238-246.

41. Bruker Analytical X-Ray System, I. APEX2, Madison, Winsconsin, USA, 2007.

42. Bruker Analytical X-Ray System, I. SAINT, Madison, Winsconsin, USA, 2007.

43. Blessing, R., An empirical correction for absorption anisotropy. Acta Crystallogr. A 1995, 51, 33-38.

44. Sheldrick, G., A short history of SHELX. Acta Crystallogr. A 2008, 64, 112-122.

45. Farrugia, L., WinGX suite for small-molecule single-crystal crystallography. J. Appl. Crystallogr. 1999, 32, 837-838. 
